\title{
Fitting Logistic IRT Models: Small Wonder
}

\author{
Miguel A. García-Pérez \\ Complutense University of Madrid
}

\begin{abstract}
State-ot-the-art item response theory (IRT) models use logistic functions exclusively as their item response functions (IRFs). Logistic functions meet the requirements that their range is the unit interval and that they arc monotonically increasing. but they impose a parameter space whose dimensions can only be assigned a metaphorical interpretation in the context of testing. Applications of IRT models require obtaining the set of values for logistic function parameters that best fit an empirical data set. However. success in obtaining such set of values does not guarantee that the constructs they represent actually exist, for the adequacy of a model is not sustained by the possibility of estimating parameters. This article illustrates how mechanical adoption of off-theshelf logistic functions as IRFs for IRT models can result in off-the-shelf parameter estimates and tits to data. The results of a simulation study are presented, which show that logistic IRT models can tit a set of data gencrated by IRFs other than logistic functions just as welt as they fit logistic data. even though the response processes and parameter spaces involved in each case are substantially different. An explanation of why logistic functions work as they do is offered, the theoretical and practical consequences of their behavior are discussed, and a testable alternative to logistic IRFs is commented upon.

Key word: goodness of fit, parameter estimation, item response theory, logistic models, fmite state. polynomic models, BH.OG
\end{abstract}

La función de respuesta al ítem (FRI) asumida en los modelos al uso en teoría de respuesta at item (TRI) es, en la práctica, exciusivamente la función logística. Las funciones logísticas cumplen los requisitos de que su rango es el intervalo $[0,1]$ y son monótonamente crecientes, pero imponen un espacio paramétrico cuyas dimensiones sólo tienen una interpretación metafórica en el contexto de la evaluación mediante pruebas objetivas. La aplicación de modelos TFi requiere la estimación de los parámetros logisticos que mejor describen unos datos empíricos. Sin embargo, el éxito en la óbtención de estos parảmetros no garantiza que los constructos representados mediante ellos existan en realidad, puesto que la validez de un modelo no queda establecida sólo por la posibilidad de estimar sus parámetros. Este trabajo muestra que la adopción mecánica de funciones logisticas como FRI en modelos TRI produce estimaciones y ajustes estereotipados. Como prueba, se presentan resultados de un estudio de simulación en el que el modelo logístico produjo un patrón de estimaciones y ajustes de datos no logísticos que fue indistinguible del patrón obtenido para datos logísticos, a pesar de que los datos no logisticos se generaron de acuerdo con un modelo que implica un proceso de respuesta y un espacio paramétrico marcadamente diferentes del logistico. El trabajo termina con unas reflexiones acerca de las razones por las que los modelos logisticos se comportan asi y de las consecuencias teóricas y prácticas de ese comportarniento, y también se describe una alternativa empiricamente falsable a las FRI Jogísticas.

Palabras clave: bondad de ajuste, estimación de parámetros, teoria de respuesta al item, modelos logisticos, modelos polinómicos de estados finitos, BLLOG

Correspondence concerning this article should be addressed to Dr. Migutel A. García-Pérez, Departamento de Metodología. Facultad de Psicología. Universidad Complutense. Campus de Somosaguas. 28223 Madrid (Spain).

Phone: (+34) 91394306 [. Fax: $(+34) 913943189$. E-mail: miguel@psi.ucm.es 
I sometimes have a nightmare about Kepler. Suppose a few of us were transported back in time to the year 1600, and were invited by the Emperor Rudolph If to set ap an Imperial Department of Statistics in the coun at Prague. Despairing of those circular orbits, Kepler enrolls in our department. We teach him the general linear model, least squares, dummy variables, everything. He goes back to work, fits the best circular orbit for Mars by least squares, puts in a dummy variable for the exceptional observation-and publishes. And that's the end, right there in Prague at the beginning of the 17 th century.

(Freedman. 1985, p. 359)

A major concem in the application of item response theory (IRT) is the estimation of item and examinee parameters. The interest arises because only when this is done can the theoretical advantages of IRT be obtained. The availability of computer programs such as LOGIST (Wingersky, Barton, \& Lord, 1982) or BILOG (Mislevy \& Bock, 1984, 1986), which estimate IRT parameters under the one-, two-, or threeparameter logistic models (1PL, 2PL, or 3PL models) has provided test practitioners with a powerful tool to harvest these benefits.

Numerous simulation studies have assessed the efficiency and accuracy with which these and other programs attain their goal in a variety of circumstances, including tests of different lengths, examinee samples of different sizes and/or different distributions of true parameters (e.g., Hambleton \& Cook, 1983; Harwell \& Janosky, 1991; Hulin, Lissak, \& Drasgow, 1982; Ree, 1979; Seong, 1990; Skaggs \& Stevenson, 1989 : Swaminathan \& Gifford, 1983; Vale \& Gialluca, 1988). Also, some papers have compared LOGIST and BILOG as to the algorithms they implement, their computational cost, and the characteristics of the estimates they provide (Mislevy \& Stocking, 1989; Yen, 1987). The results of all these studies provide a positive outlook of the performance of the programs, as the gencrating parameters could successfully be recovered in the vast majority of cases.

The capability of logistic models to fit artificjal data that violate the assumptions of local independence and unidimensionality has also been explored (Ansley \& Forsyth, 1985; Drasgow \& Parsons, 1983; Forsyth, Saisangjan, \& Gilmer, 1981; Harrison, 1986; McKinley \& Mills, 1985; Reckase, 1979; Yen, 1984). Although these studies showed that logistic functions can fit this type of data and provide parameter estimates, attention to the issue of the extent to which the model fitted the data was only paid by McKinley and Mills.

The extent to which logistic models can fit data sets generated by a different model has also occasionally been assessed. Some studies showed that data generated by logistic models of various numbers of parameters can be fitted to logistic models of fewer parameters (e.g., Dinero \& Hatrtel, 1977; Yen, 1981), and Wood (1978) showed that the 1PL model can fit data generated by a coin-toss process, thus "recovering" fictitious parameters. Mislevy and Verhelst (1987) also showed that the IPL model can fit a mixture of data generated by a random-guessing process and by the IPL model itself. All these studies authenticate Bejar's (1983, p. 3) concern that "unfortunately, the programs that [estimate logistic parameters] are capable of returning reasonablelooking estimates even when the dala are totally inappropriate for the model assumed by the program. That is, succeeding to estimate the parameters of the model does not insure that wo have successfully fitted the model."

The research mentioned in the foregoing paragraphs has systematically failed to acknowledge properly that the choice of the logistic function as the item response function (IRF) for IRT models is an assumption of the theory (Hambleton \& Swaminathan, 1985, pp. 9-10; Lord, 1980, p. 30; Weiss \& Yoes, 1991, p. 74), one whose adequacy must be checked. Yet, on describing how to address the determination of model/data fit, Hambleton and Swaminathan (1985, chap. 8; see also Hambleton \& Murray, 1983) did not list the IRF as an assumption to be checked. It seems that the adequacy of logistic IRFs has been taken for granted, and it is noteworthy that, paying little heed to Bejar's (1983) cautionary comment, practitioners are content with estimating logistic parameters without considering the issue of model/data fit any further than whether the 1PL, 2PL, or 3PL model should be chosen. Indeed, Mislevy and Stocking (1989, p. 57) state that obtaining the advantages of IRT "requires access to flexible and economical computer programs to estimate IRT parameters for items, examinees, and populations of examinees," neglecting to mention that, to begin with, the model should fit the data. The belief seems to have been cstablished that logistic IRFs exist in the real world for computer programs to hunt for the parameters that characterize each conceivable item, and that only some know-how is needed to adjust the options of these programs in order to arrive at the solution that was there to be found (see Mislevy \& Stocking, 1989, p. 68). Thus, work on IRT has almost exclusively focused on the development and comparison of parameter estimation techniques and the study of the effects of characteristics of the data sets (sample size, test length, and distribution of the true parameters) and violations of model assumptions (excluding the mathenatical form of the IRF) on the capability of available algorithms to recover the generating parameters (Baker, 1987a, 1987b, 1991, 1998; De Ayala, 1992; Gifford \& Swaminathan, 1990; Jannarone, Yu, \& Laughlin, 1990; Kim \& Nicewander, 1993; Kim, Cohen, Baker, Subkoviak, \& Leonard, 1994; Lord, 1986; Mislevy, 1987; Swaminathan \& Gifford, 1986; Tsutakawa, 1992; Tsutakawa \& Johnson, 1990; Tsutakawa \& Lin, 1986; Tsutakawa \& Soltys, 1988; Wainer \& Thissen, 1987; Wang \& Vispoel, 1998; Warm, 1989; Weitzman, 1996; Zeng, 1997). No one seems to have questioned whether, in the real world, logistic item and examinee parameters are actually there to be recovered or, in other words, whether the mathematical form of the IRF can be derived from a 
psychological theory of performance in objective tests as opposed to adopting a convenient function that the data are forced to fit by fiat.

It is understandable that there has been little discussion in the litetature as to what mathematical form and what parameter space the IRF should hold, as there are no competing IRFs that are substantively different from logistic functions. By "substantively different," we mean functions that have theoretical underpinnings and whose paramelers have theoretically sound interpretations. This characteristic prevents splines (Ramsay \& Abrahamowicz, 1989), chosen with the only criterion of being more flexible than logistic functions, from being eligible as plausible replacements for them. As Goldstein and Wood (1989; see also Blinkhorn, 1997) pointed out, IRT has developed with a stunning distegard for psychological theory which might provide theoretically sound IRFs as replacements for logistic functions. In the past lew years we have proposed, developed, and tested a model of performance in objective tests (García-Pérez, 1985, 1987, 1989b, 1990, 1993; see also García-Perez \& Frary, 1989, 1991a) that is central to the work described here.

This paper aims at investigating the capability of logistic functions to fit antificial data generated from IRFs that differ in their resemblance to logistic functions in several aspects. Thus, the paper is similar to Wood's (1978) in its goal, but it differs in three major respects. First, more realistic generatjng models, involving different and interpretable parameter spaces, are used. Second, the $1 \mathrm{PL}, 2 \mathrm{PI}$, and $3 \mathrm{PL}$ models are all fitted to the generated data. Third, some practical recommendations are given. and an alternative way to define and test (as opposed to merely fit) IRFs for use with IRT models is described. PC-BILOG (Mislevy \& Bock, 1986) was used to obtain the logistic parameterizations. There is reason to believe that other programs would have performed just as PC-BILOG did in the situations that will be described below (see Mislevy \& Stocking, 1989; Yen, 1987).

The paper is divided into two studies. In the first, a data set was generated by the 3PL model and another set was generaled by a slight modification of the 3PL model. The analysis of the $3 \mathrm{PL}$ parameterization of $3 \mathrm{PL}$ data serves as a baseline with which the rest of the results are compared. The analysis of the data generated by modifying the 3PL model indicates how minor differences between generating and fitted models affect the fit and the recovery of the (still logistic) true parameters. For the second study, data were generated by two different finite state polynomic models (García-Pérez \& Frary, 1991a). These models represent major departures from the assumption of underlying logistic IRFs and their associated parameter spaces and, therefore. provide for a more stringent lest of the capability of logistic functions to "recover" fictilious parimeters.

\section{General Procedure}

Responses of 500 examinees to a four-option 50-item test were simulated using four different generating models which will be described in detail below. ${ }^{1}$ Random numbers required at several points in the programs were obtained as described by Wichmann and Hill (1982). The programs created data files which were subsequently inpur to $\mathrm{PC}$ BILOG to obtain examince and item parameter estimates as well as measures of fit for the test and the individual items.

Each of the four data sets was subject to three PCBILOG runs in order to obtain their 1PL, 2PL, and $3 \mathrm{PL}$ parameterizations. Default options for PC-BILOG were used throughout, and the metric of the logistic function was chosen. Default options do not always guarantee best fit, but using the same options in all cases serves the more relevant goal of making results comparable across data sets. By default, PC-BILOG considers omissions as wrong responses when the $3 \mathrm{PL}$ model is fitted. Since two of the data sets included omissions, a fourth PC-BHLOG run on each of them sought to obtain their 3PL parameterizations when omissions are treated as fractionally correct responses. The 3PI. model fitted with this choice for the treatment of omissions will be called 3PL-C.

From each PC-BILOG run, a number of statistics and estimates were obtained for further analysis. These included the measure of overall fit given by the marginal loglikelihood statistic ( $-2 \log L$ ), the approximate chi-square index of fil fot every item, the estimated item parameters, and the estimated examinee abilities. On analyzing these measures, the following issues were specifically addressed in each of the four simulations:

1. Variations in overall fit, as given by the marginal log likelihood statistic, as a function of the correspondence (or lack thereof) between the generating and the fitted model.

2. Variations in the distribution of the fit of individual items, as given by the approximate chi-square indexes within each fitted model.

3. The relationships between the various estimated item parameters within each fitted model and across the various fitted models.

4. The relationship between true and estimated item parameters within each fitted model.

\footnotetext{
1 Sample size and test length were chosen to be large enough (yet reasonahly small) to minimize estimation emors caused simply by scarcity of data. It should be noted that Baker (1998) concluded from simulation studies that data sets of 500 examinees and 50 items yicld excellent item parameter tccovery by BILOG.
} 
5. The relationships between estimated examinee abilities across different fitted models.

6. The relationship between true and estimated examinee abilities within each fitted model.

It should be kept in mind that our goal is to determine the extent to which logistic models can fit data generated using models which differ from the fitted models in several aspects. Therefore, the study does not address the possible effects of varying the true parameter distributions, the number of options per item, the length of the test, or the number of examinees. The choices that are made below about these characteristics are hence of no concern with respect to the outcomes of this study.

\section{Study 1: Fitting Logistic Models to Logistic Data}

\section{Generating Models}

The first data set for this study was generated from the conventional 3PL model equation

$$
P_{i}\left(\theta_{j}\right)=c_{i}+\frac{1-c_{i}}{1+\exp \left[-a_{i}\left(\theta_{j}-b_{i}\right)\right]},
$$

where $b_{i}, a_{i}$, and $c_{i}$ are, respectively, the difficulty, discrimination, and pseudo-chance level parameters of item $i$, and $P_{i}\left(\theta_{j}\right)$ is the probability that examinee $j$, with ability $\theta_{i}$, answers item $i$ correctly. This generating model will be referred to as $3 \mathrm{PL}$.

The second data set was generated by adding to the $3 \mathrm{PL}$ generating model the disturbance described by Mislevy and Bock (1986, p. 5-17) to allow a small number of omissions. Examinees responded according to Equation I whenever $P_{i}\left(\theta_{j}\right)$ $\geq .3$, and otherwise they had a .5 probability of omitting. Exarninees who did not omit when $P_{i}\left(\theta_{j}\right)<.3$ also responded according to Equation 1. The generating model resulting from this modification will be referred to as 3PL-O.

\section{True Parameters}

For the two simulations, 500 values to represent examinee true abilities were randomly generated to be distributed $N(O$,
1). Similarly, item difficulties were generated to be uniformly distributed in $[-2.0,2.0]$ and item discriminations to be uniformly distributed in $[0.6,2.0]$, whereas pseudo-chance level parameters were kept constant at .25 for all items. ${ }^{2}$ The observed $\theta$ distribution had a mean of .005 and a standard deviation of 958 , with a minimum of -2.79 and a maximum of 2.80. Observed item difficulties ranged from -1.98 to 1.99 , with a mean of 0.159 and a standard deviation of 1.143, and observed item discriminations ranged from 0.603 to 1.984 with a mean of 1.338 and a standard deviation of 0.430 . The product-moment correlation between difficulty and discrimination was $r=.07$.

\section{Results and Discussion}

Table 1 gives the values of $-2 \log L$ obtained for every model fitted to each data set. ${ }^{3}$ For 3PL data, fitting the 3PL model resulted in the best $-2 \log L$. For these data, the difference between the 3PL and 1 PL parameterizations in terms of $-2 \log L$ was 371.42 , and the difference between the 3PL and 2PL parameterizations was 113.66. Of course, the cost of these improvements was, respectively, to estimate 100 or 50 more parameters. The situation for 3PL-O data is about the same, but it is noteworthy that fitting the 3PL$C$ model resulted in a value of $-2 \log L$, which was much worse than that obtained when fitting the IPL model. This is probably a consequence of the inappropriateness of default PC-BILOG options for data including omissions. No attempt was made to run PC-BILOG with different options to improve the fit, because obtaining the best possible fit was not a goal of this study.

$I_{t}$ is interesting to note that the disturbance in the 3PL$O$ model did not have a strong effect in model/data fit, provided that omissions are treated as wrong respotises when fitting the $3 P L$ model. In fact, the pattem of $-2 \log L$ values across the fitted $1 \mathrm{PL}, 2 \mathrm{PL}$, and 3PL models is similar for the data with and without omissions. On the other hand, large degrees of mismatch between the generating and the fitted model, as represented by the 2PL and IPL parameterizations, resulted in a deterioration of the fit. In short, when the same PC-BILOG options are used, the fit scems to be best when the fitted model matches the generating model and, when the 3PL model is fitted to data

2 These choices might be disdained as non-realistic. However, similar choices were made by Swaminathan and Gifford (1983). Hambleton (1983) or Baker (1998), and it should be kept in mind that "notions of what 'realistic' means are determined by what available programs provide, and programs do not necessarily provide the true parameters for any dataset of reasonable size" (Mislevy \& Stocking, 1989. p. 73). In any case, this type of realism is not relcvant to the goal of this paper and, in addition, the results to be presented below indicate that the possibility of a logistic parameterization of a test is not hampered by this choice for the distributions of the generating parameters.

3 It should be remembered that likelihood is a function of the data and. then, only comparisons across models fitted to the same data are legitimate. Also. direct comparison of values of $-2 \log L$ gives only a crude indication of fil, but their chi-square approximation is suspect. Also note that, for any given data set, each fitted model lies in a boundary of the next higher-djmensional model, which further lessens the validity of $-2 \log L$ as true clui-squares (for a similar treatment of $-2 \log L$, see Mislevy \& Verhelst. 1987). 
with omissions, the best choice secms to be to treat omissions as wrong responses. Whether or not this is true in general will be left unexplored here because it is beyond the goal of this paper.

Table 1

Values of $-2 \log L$ in Study I

\begin{tabular}{ccr}
\hline & \multicolumn{2}{c}{ Generating Model } \\
Fitted Model & $3 \mathrm{PL}$ & $3 \mathrm{PL}-\mathrm{O}$ \\
\hline IPL & 28478.62 & 27835.87 \\
$2 \mathrm{PL}$ & 28220.86 & 27503.89 \\
3PL & 28107.20 & 27482.93 \\
3PL-C & - & 28317.71 \\
\hline
\end{tabular}

Table 2 summarizes the information provided by the approximate chi-square inflex of fit for each item. ${ }^{4}$ Because degrees of freedom varicd across items and across fitted models, the $p$-values of the approximate chi-square statistics are reported instead of their values. As cin be seen, the IPL parameterization results in poorer fits for the items, with an importam number of them having $p$-valucs below .05 . In contrast, the 2PL and 3PL parameterizations result in approximately equally good fits, with only a few misfitting items. It is noteworthy that when the 3PL-C model was fitted to 3PL-O data, the deterioration of fit indicated by the -2 $\log L$ statistic in Table 1 does not show at the item level.

Using a modificd version of Yen's (1981) criteria for choosing the most appropriate fitted model (amended to replace a comparison of the mean values of the itcm fit statistics with a comparison of their mean $p$-values), the

(a) 3PL data
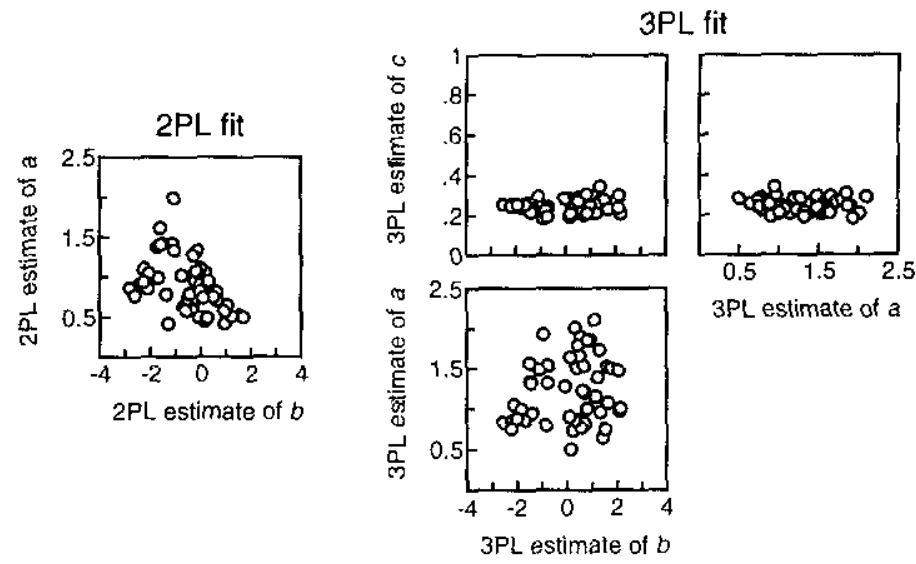

(b) 3PL-O data
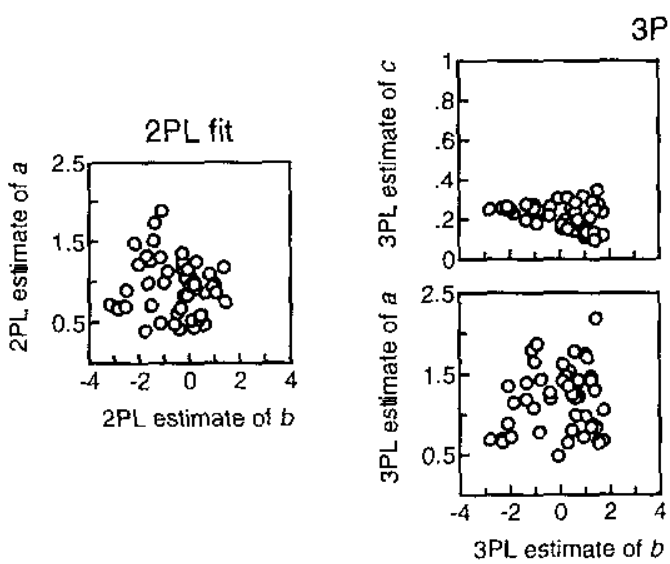

SPL fit

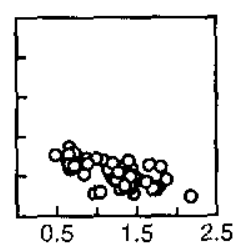

$3 \mathrm{PL}$ estimate of $a$

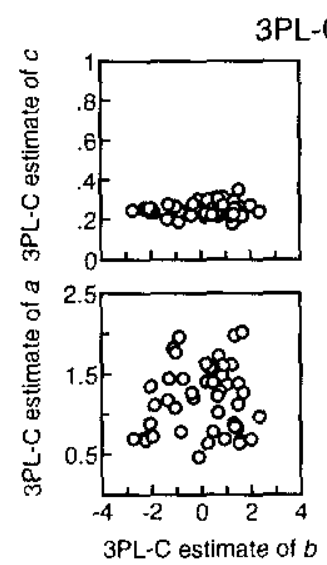

Figure /. Relations between estimated logistic parameters within each fitted logistic model. (a) 3PL data. (b) 3PL-O data.

4 These indexes of fit should be interpreted with caution, since they are not true chi-square statistics. 
Table 2

Means and Standard Deviations of p-values, and Number of Misfitting Items $(p<.05)$ in Study 1

\begin{tabular}{|c|c|c|c|c|c|c|}
\hline \multirow{3}{*}{$\begin{array}{l}\text { Fitted } \\
\text { Model }\end{array}$} & \multicolumn{6}{|c|}{ Generating Model } \\
\hline & \multicolumn{3}{|c|}{$3 P L$} & \multicolumn{3}{|c|}{$3 P L-O$} \\
\hline & $M$ & $S D$ & $N$ & $M$ & $S D$ & $N$ \\
\hline $1 \mathrm{PL}$ & 0.36 & 0.29 & 1,3 & 0.42 & 0.33 & 8 \\
\hline 2PL & 0.55 & 0.28 & 1 & 0.60 & 0.30 & 3 \\
\hline 3PL & 0.55 & 0.27 & 1 & 0.60 & 0.28 & 2 \\
\hline 3PL-C & - & - & - & 0.58 & 0.33 & 1 \\
\hline
\end{tabular}

IPL model should be rejected for these data, but a decision about the appropriateness of the 2PL vs 3PL models cannot be made from the values of the statistics reported so far. The differences between these two latter parameterizations are further examined next.
Figure 1 shows the relationships between the various item parameters estimated within aach fitted model. For 3PL data (Figure 1a), fitting the 2PL model results in a negative relationship between estimated difficulty and discrimination $(r=-.45)$, whereas this relationship almost vanishes when the appropriate 3PL model is titted ( $r=.19)$. It should be remembered that true difficulty and discrimination did not bear any relation $(r=.07)$. In addition, there is no cvidence of any relationship between pseudochance level estimates and the wo other 3PL parameter estimates $(|r|<.14)$.

For 3PL-O data (Figure $1 b$ ), the situation is not very different for the 2PL and 3PL models when omissions are treated as fractionally correct responses (2PL and 3PL-C lit, respectively). Yet, when omissions are treated as wrong responses (3PL fit), pseudo-chance level cstimates are negatively related to estimated discrimination ( $r=-.65)$, and their spread around the true value of .25 increases with increasing estimated difficulty. (a) 3PL data; 2PL vs 3PL fit

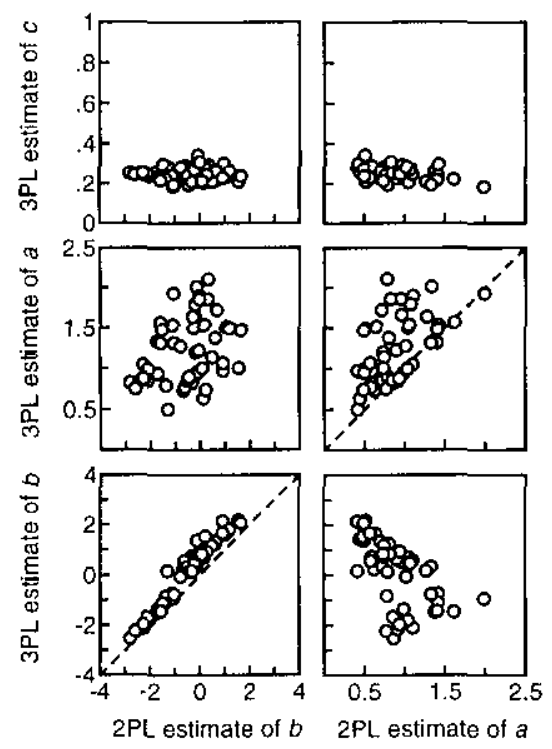

(b) 3PL-O data; 2PL vs 3PL fit

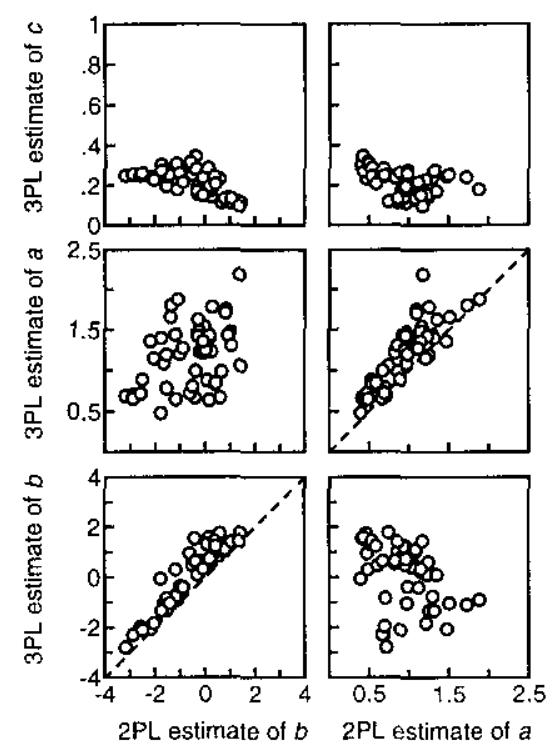

(c) 3PL-O data; 2PL vs 3PL-C fit

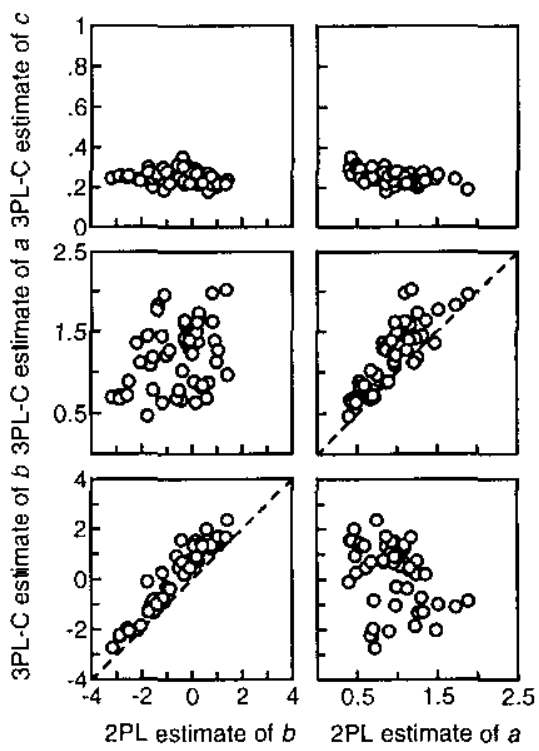

(d) 3PL-O data; 3PL vs 3PL-C fit
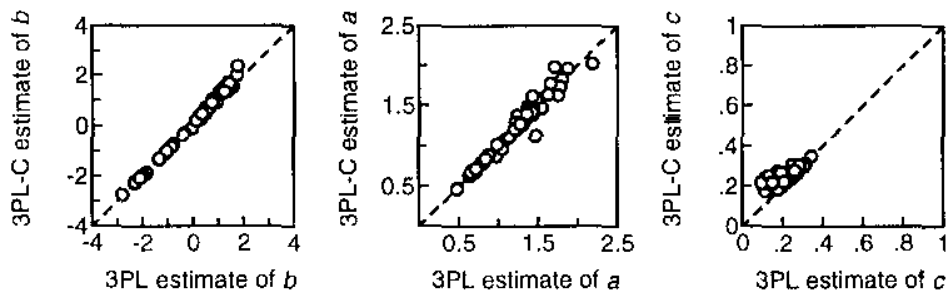

Figure 2. Relations between estimated logistic parameters across different fitled logistic models. (a) 2PL vs 3PL estimates for 3PL data. (b) 2PL vs 3PL estimates for 3PL-O data. (c) 2PL vs 3PL-C estimates for 3PL-O data. (d) 3PL vs 3PI-C estimates for 3PL-O data. Dashed diagonal lines indicatic an expected identity relationship betwon the variables in the abseissa and the ordinace. 
Figure 2 shows how the estimates vary across fitted models. For 3PL data (Figure 2a), 2PL and 3PL difficulty estimates are similar and highly lincarly related $(r=.97)$, but $2 \mathrm{PL}$ and $3 \mathrm{PL}$ discrimination estimates are not so closcly related $(r=.53)$, with values for the 3PI parameterization being generally larger than those resulting from the $2 \mathrm{PL}$ fit. The presence of this type of relationship between 2PL and 3PL discrimination estimates was regarded by Yen (1981) as evidence that the 2PL model is inappropriate for the dati. Finally, items for which 3PL pseudo-chance level estimates deviate the most from the true value of .25 tend to obtain average $2 \mathrm{PL}$ difficulty estimates.

In contrast, for 3PL-O data (Figure 2b) the presence of omissions breaks up slightly the relationship between $2 \mathrm{PL}$ and 3PL difficulty estimates $(r=.93)$, and brings the 2PL and 3PL discrimination estimates closer than they were in the absence of omitted tesponses $(r=.84)$. On the other hand, 3PL pseudo-chance levels noticeably tend to be estimated well below their true value for items that simultaneously obtain high 2PL difficulty and average 2PL discrimination estimates. The relationships between $2 \mathrm{PL}$ and 3PL-C estimates (Figure $2 \mathrm{c}$ ) are similar to those shown in Figure 2b, except that 3PL-C pseudo-chance level estimates bear with $2 \mathrm{PL}$ difficulty and discrimination estimates a similar relation as they did for data without omissions (compare with Figure 2 a). Therefore, it would seem that, as far as a comparison between 2PL and 3PL or 3PL-C item estimates is concerned, the only meaningful difference between the two options for the treatment of omissions shows in the estimation of pseudo-chance levels. This is best seen in Figure 2d: the different treatments of omissions do not affect item difficulty estimates, slightly affect discrimination estimates for items of high estimated discrimination, and substantially affect pseudo-chance level estimates.

To determine whether these characteristics affect items within specific ranges of true parameters, the relationships between true and estimated item parameters were explored within each fitted model. Figure 3 a shows the relationships between true difficulty and discrimination and their $2 \mathrm{PL}$ estimates for 3PL data. Figure $3 b$ does the same for 3PL$O$ data. In both cases, difficulty seems to be slightly underestimated by the 2PL model, but the estimates are highly correlated with true difficulty $(r=.97$ and $r=.96$ in Figures $3 \mathrm{a}$ and $3 \mathrm{~b}$, respectively) and virtually uncorrelated with true discrimination ( $r=.23$ and $r=.27$ ). Conversely, 2PL discrimination estimates are less strongly related to true discrimination $(r=.61$ and $r=.83)$ and they are negatively related to true difficulty $(r=-.56$ and $r=-.28$ ). Consistent with Yen's (1981) interpretation of the way in which the absence of a third parameter is made up for when the 2PL model is fitted to 3PL data, Figures $3 a$ and $3 b$ show that the underestimation of $2 \mathrm{PL}$ discrimination afrects items of high true difficulty and discrimination. (a) 3PL data; $2 \mathrm{PL}$ fit

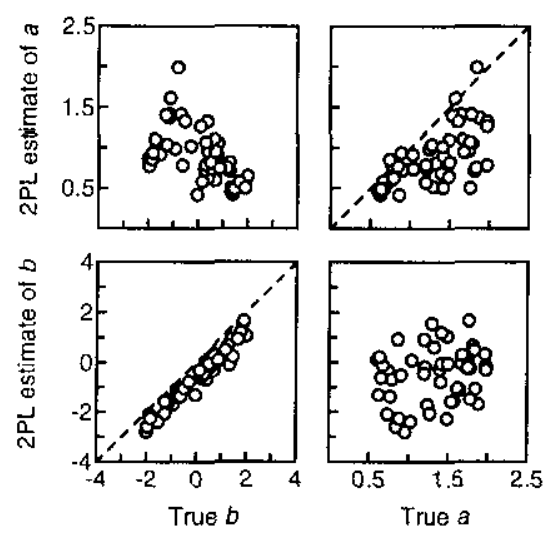

(b) 3PL-O data; 2PL fit

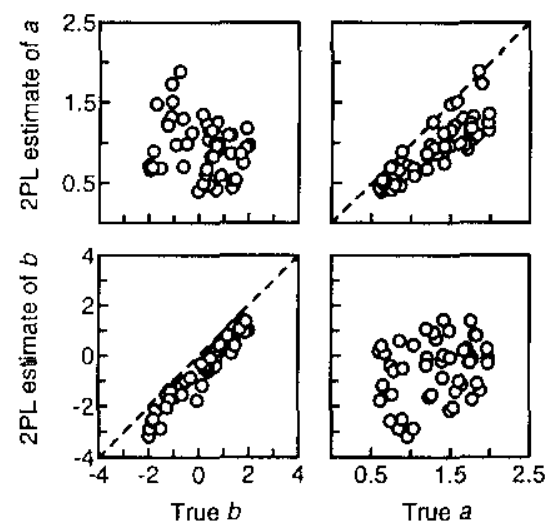

Figure 3. Relations between true $a$ and $b$ and 2PL estimates. (a) 3PI data. (b) 3PI_O data. Dashed diagonal lines indicate an expected identity relationship between the variables in the abscissa and the ordinate.

The relationships between true parameters and their 3PL estimates (for 3PI and 3PL-O data) or their 3PL-C estimates (for $3 \mathrm{PL}-\mathrm{O}$ data) are shown in Figures $4 \mathrm{a}, 4 \mathrm{~b}$, and $4 \mathrm{c}$, respectively. In all three cases, difficulty estimates are very close and linearly related to true difficulty $(r>97)$, and they bear no relation to true discrimination $(|r|<.06)$. Estimated discriminations are only slightly less related $t o$ the true values $(.86<r<.90)$, but they do not bear any relation to true difficulty $(|r|<.19)$. On the other hand, pseudo-chance level estimates are unrelated to true difficulty and discrimination, except when omissions are treated as wrong responses (Figure 4b), where they show signs of a negative relation to true difficulty $(r=-49)$ and discrimination $(r=-.62)$.

As for examinec ability, the relations among the estimates obtained from the various models fitted to each data set are shown in Figure 5, revealing that ability estimates are almost 
(a) 3PL data; 3PL fit

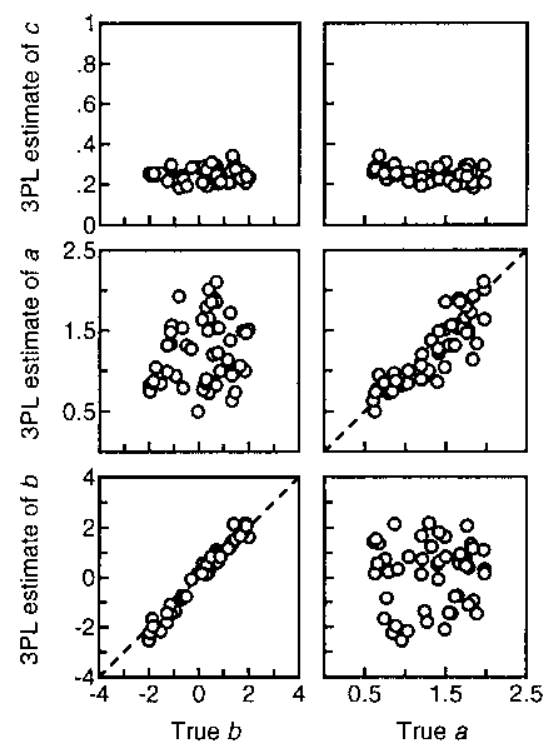

(b) 3PL-O data; 3PL fit

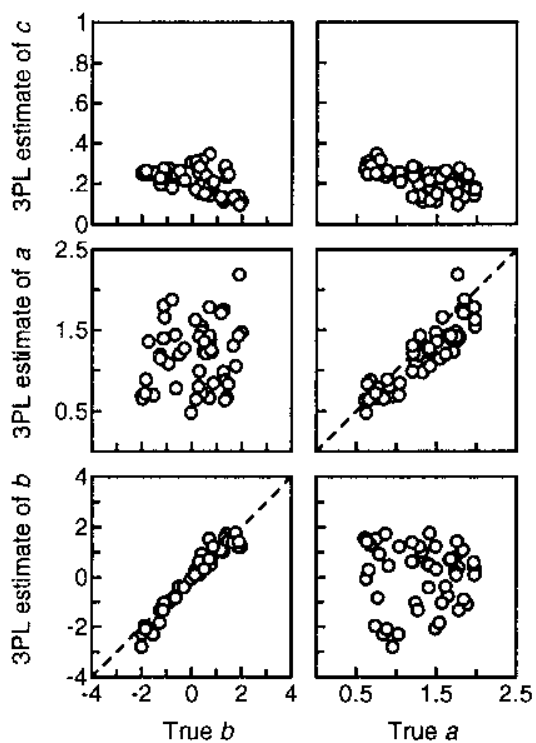

(c) 3PL-O data; 3PL-C fit

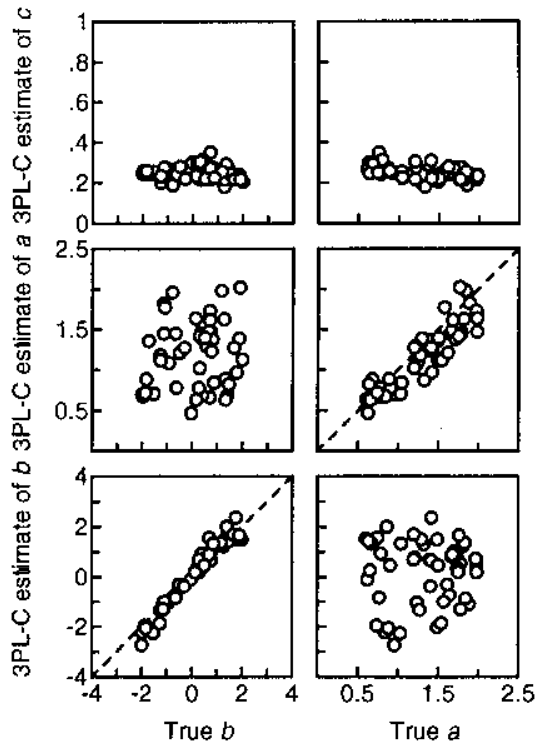

Figure 4. Relations between true $a$ and $b$ and 3PL estimates. (a) 3PL fit to 3PL data. (b) 3PL fit to 3PL-O data. (c) 3PL-C fit to 3PL$O$ data. Dashed diagonal lines indicate an expected identity relationship between the variabies in the abscissa and the ordinate.
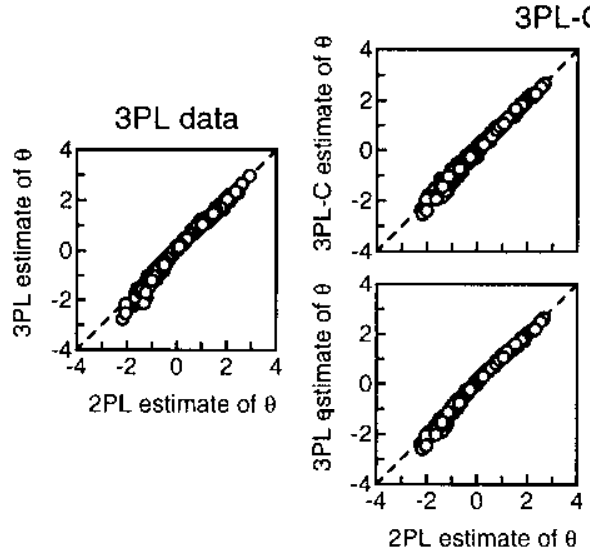

Figure 5. Relations between estimated logistic abilities across models fitted to each datit set. Dashed diagonal lines indicate an expected identity rclationship between the variables in the abscissa and the ordinate. the same throughout $(r>99)$. Figure 6 shows that all ability estimates are also about equally related to true ability (.92 $<r<$ 94) no matter which model was used to generate the data or how omissions were treated. It is also clcar from a comparison of Figures 5 and 6 that the different ability estimates are much closer to each other than any of them is to true ability.

\section{Conclusion}

The main goal of this first study was to obtain a 3PL parameterization of 3PL data that could set a standard of comparison for the parameterizations obtained for data differing from 3PL data in several aspects. In the first simulation, where data were generated to match both the parameter space and the response process that the fitted model assumes, the 3PL parameterization recovered the true
3PL data

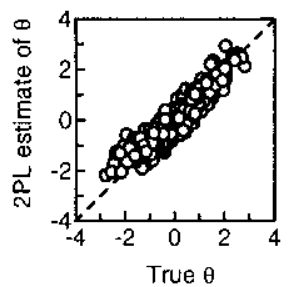

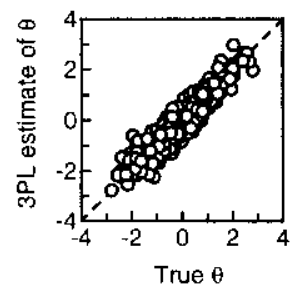
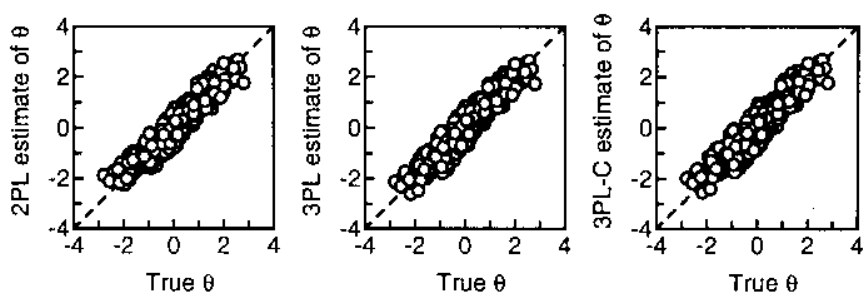

Figure 6. Relations between true and estimated logistic abilities across models fitted to each data set. Dashed diagonal lines indicate an expected identity relationship between the variables in the abscissa and the ordinate. 
parameters reasonably well. In the second simulation, where generating and fitted models shared the parameter space but implied slightly different response processes, the 3PL parameterization could also recover the true parameters. In both simulations, the recovery was far from perfect, with noticeable errors in the item discrimination parameters and, to a lesser extent, in the item difficulty and examinee ability parameters. In agreement with results of Yen (1981) and McKinley and Mills (1985), differences between 2PL and 3PL parameterizations were minimal, as were those between 3PL parameterizations obtained with different options for the treatment of omissions.

These analyses have focused on the recovery of parameters as well as on the relationships among estimated parameters across and within fitted models. The issue of the recovery of IRFs (i.e., whether the shape of the estimated IRF approximates that of the true IRF regardless of differences between estimated and true parameters) has not been addressed because the recovery of parameters was indeed sufficiently accurate. These results characterize the performance of logistic model parameter estimation techniques when generating and fitted models match or almost match. The next study explores how these techniques behave when the differences between generating and fitted models are more dramatic.

\section{Study 2: Fitting Logistic Models to Finite State Polynomic Data}

\section{Generating Models}

Each of the two data sets on which this study is based was generated using a different finite state polynomic (FSP) model. A thorough description of these models can be found in García-Pérez and Frary (199/a), but a brief introduction follows. FSP models were developed in the context of measurement of educational achievement, and they include two examinec parameters and an item parameter. The main examinee parameter, $\lambda(0 \leq \lambda \leq 1)$, represents ability or level of knowledge and bears no relation to its logistic counterpart $\theta$. In finite state theory, $\lambda$ stands for the proportion of statements about a subject matter whose truth value the examinee knows. Thus, unlike $\theta$ in logistic models, $\lambda$ is directly interpretable as the proportion of knowledge that the examinee has. (Out of the context of domain-referenced testing, or simply to avoid sampling considerations, a less stringent definition of $\lambda$ is that it is the proportion of statements on a test that the examinee knows.) On a test, a statement is represented by the completion of an item stem with any one of its response options. Thus, the probability of an examinee's identifying a randomly drawn option in a randomly drawn item as the correct answer or a distractor is, before considering item chanacteristics, simply $\lambda$.
The FSP item difliculty parameter $\delta(0<\delta<1)$ modifies this probability. Like $\lambda, \delta$ bears no relation to its logistic counterpart $b$. It characterizes items from the difficult $(\delta \rightarrow 0)$ to the easy $(\delta \rightarrow 1)$, and interacts with $\lambda$ to determine the probability of an examinee's identifying an option in a certain item as its correct answer or a distractor. García-Pérez and Frary (199la) proposed a mathematical form for the interaction between examinee ability and item difficulty, but that equation was later amended by García-Pérez (1994). Here we will adopt the latter form so that the probability that an examinee of ability $\lambda_{j}$ knows the truth value of an option in an item of difficulty $\delta_{i}$ is

$$
p_{i j}=\lambda_{j}^{-\log \delta_{i}}
$$

This equation has a more natural interpretation than the original proposal because the effects of $\lambda$ and $\delta$ are symmetric. Specifically, for a statement of average difficulty $(\delta=5)$, the probability that an examinee of ability $\lambda$ knows its truth value becomes just $\lambda$; similarly, for an examinee of average ability $(\lambda=.5)$ the probability that he/she knows the truth value of a statement of difficulty $\delta$ becomes just $\delta$. In other words, an examinee's $\lambda$ is interpretable as the probability of his/her knowing the truth value of statements of average difficulty, whereas a statement's $\delta$ is interpretable as the probability that its truth value be known by cxaminees of average ability.

On a multiple-choice test, the probability that an examince responds correctly to an item is definitely a function of this basic probability as applied to each of the options in the item, but it also depends on a number of other factors, among which guessing is included. This calls for the second examinee parameter, $\gamma(0 \leq \gamma \leq 1)$, which represents the examinee's willingness to guess when unsure of the answer, regardless of how many distractors they had the knowledge to identify. This parameter has no parallel in logistic models and represents the probability that an examines will guess at random among the unclassified options (as opposed to onitting) when unsure of the correct answer to an item.

García-Pérez and Frary (1991a) discussed some other assumptions about examinee behavior and test and item characteristics reflecting leatures of the testing situation that can be taken into account to derive a matching FSP model. These assumptions cover the guessing strategy of the examinees, the number of options per item, the relative identifiability of correct answers vs distractors, the format of administration of the test, and other item characteristics such as use of "none of the above" (sce also Garcia-Pérez, 1993; García-Pérez \& Frary, 199 (b). They also exemplified the procedure for developing FSP models and provided a number of models that incorporate different sets of assumptions. "Two of these were selected for the simulations carried out here. 
Data for the second simulation were generated using Equations 3a-3c of García-Pérez and Frary (1991a). Those equations embody the model for a four-option test administered with the conventional format (i.e., asking examinees to mark the correct option), in which distractors are as easily classifiable as correct answers, and where examinees guess without following any consistent strategy. This type of examinee behavior was referred to as random omission (RO) by García-Pérez and Frary (1989). The corresponding generating model, which we will reter 10 as FSP-RO, is given by

$$
\begin{gathered}
c_{i j}=p_{i j}^{4}+4 p_{i j}^{3}\left(1-p_{i j}\right)+3 p_{i j}^{2}\left(1-p_{i j}\right)^{2}+\frac{3}{2} p_{i j}^{2}\left(1-p_{i j}\right)^{2} \gamma_{j}+ \\
p_{i j}\left(1-p_{i j}\right)^{3}+p_{i j}\left(1-p_{i j}\right)^{3} \gamma_{j}+\frac{1}{4}\left(1-p_{i j}\right)^{4} \gamma_{j},
\end{gathered}
$$

$$
w_{i j}=\frac{3}{2} p_{i j}^{2}\left(1-p_{i j}\right)^{2} \gamma_{j}+2 p_{i j}\left(1-p_{i j}\right)^{3} \gamma_{j}+\frac{3}{4}\left(1-p_{i j}\right)^{4} \gamma_{j},
$$

$$
\begin{aligned}
u_{i j}= & 3 p_{i j}^{2}\left(1-p_{i j}\right)^{2}\left(1-\gamma_{j}\right)+3 p_{i j}\left(1-p_{i j}\right)^{3}\left(1-\gamma_{j}\right)+ \\
& \left(1-p_{i j}\right)^{4}\left(1-\gamma_{j}\right)
\end{aligned}
$$

with $p_{i j}$ as in Equation 2. Equations 3a-3c, respectively, represent the probabilities that an examinee of ability $\lambda_{j}$ and willingness to guess $\gamma_{j}$ responds correctly, wrongly, or leaves unanswered an item of difficulty $\delta_{i}$. Figure 7 plots the IRF of Equation $3 a$ for various $\gamma$ and $\delta$. Note that, in addition to providing an equation for the probability of a correct response to an item under the conditions assumed for the test, FSP models also supply equations for the probabilities of a wrong response and an omission and, in general, for every outcome that may occur under any format of administration.

Data for the first simulation were generated by a variant of this model which differed only in that examinces were assumed to altempt all the items by guessing whenever necessary, a behavior that was referred to as number correct (NC) by García-Pérez and Frary (1989). This behavior is often cncouraged on evidence of the major effects of differential guessing strategies on test scores (Albanese, 1988: Bliss, 1980; Cross \& Frary, 1977; Rowley \& Traub, 1977; Slakter, 1968). The equations for this generating model, which will be referred to as FSP-NC, are straightforwardly obtained from Equations $3 \mathrm{a}-3 \mathrm{c}$ by noting that NC behavior makes $\gamma_{j}=1$ for all examinees. When this substitution is made, the right-hand side of Equation $3 \mathrm{c}$ reduces to 0 and, not unexpectedly, the model reflects that omissions do not occur under this guessing strategy.

Note that, as a consequence of this choice of models, this study also used a data set in which there were no omitted responses and a data set in which there were omissions.

\section{True Parameters}

For both simulations, 500 values to represent examinee abilities were randomly drawn to be uniformly distributed in $(1,9)$. Another set of 500 values to represent examinee willingness to guess was generated to be uniformly distributed in $[0,1]$. Item difficulties were generated to be uniformly distributed in $(.1, .9)$. The observed $\lambda$ distribution had a mean of .520 and a standard deviation of .227 , with a minimum of .103 and a maximum of 899 ; the observed $\gamma$ distribution ranged from .001 to .999 , with a mean of .501 and a standard deviation of $.288 ; \lambda$ and $\gamma$ correlated $r=.04$. Finally, observed $\delta$ s ranged from .104 to .886 with a mean of .529 and a standard deviation of .234 . (a) $\gamma=0$

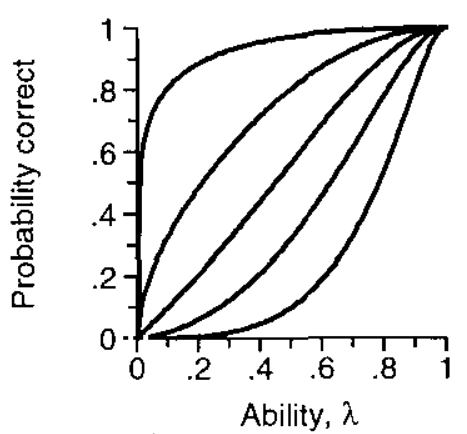

(b) $\gamma=1 / 3$

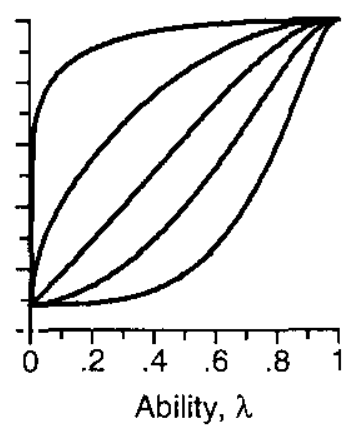

(c) $\gamma=2 / 3$

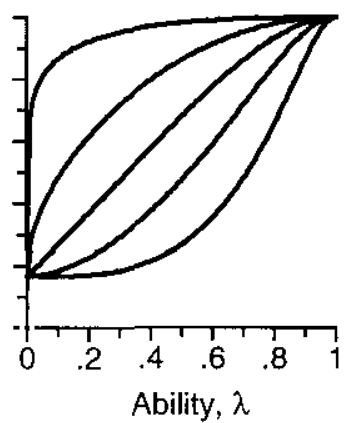

(d) $\gamma=1$

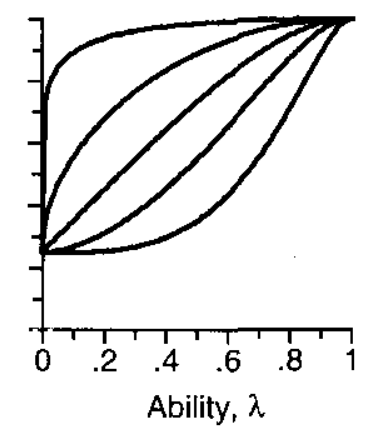

Figure 7. Finite state polynomic IRFs given by Equation 3 a for various $\gamma \mathrm{s}$. In each panel, curves represent, from top to bottom, IRFs for items with $8 \mathrm{~s}$ of $.9,7, .5, .3$, and .1 . 
Table 3

Values of $-2 \log L$ in Study 2

\begin{tabular}{ccc}
\hline & \multicolumn{2}{c}{ Generating Model } \\
\cline { 2 - 3 } Fitted Model & FSP-NC & FSP-RO \\
\hline IPL & 22484.12 & 23231.31 \\
2PL & 22406.22 & 23172.29 \\
3PL & 22334.31 & 23182.51 \\
3PL-C & - & 23263.97 \\
\hline
\end{tabular}

\section{Results and Discussion}

Values of $-2 \log L$ for all the models fitted in each simulation are shown in Table 3. Within each data set, the values of $-2 \log L$ resulting from the different fitted models are much closer together than they were in the previous study. For FSP-NC data, the value of $-2 \log L$ improves by 77.90 when the 2PL model is fitted instead of the IPL model, and by 71.91 when the $3 \mathrm{PL}$ model is fitted instead of the $2 \mathrm{PL}$
Table 4

Means and Standard Deviations of p-values, and Number of Misfiting hems $(p<.05)$ in Study 2

\begin{tabular}{cccccccc}
\hline & \multicolumn{4}{c}{ Generating Model } \\
\cline { 2 - 5 } \cline { 5 - 8 } Fittcd & \multicolumn{3}{c}{ FSP-NC } & & \multicolumn{3}{c}{ FSP-RO } \\
\cline { 2 - 8 } Model & $M$ & $S D$ & $N$ & $M$ & $S D$ & $N$ \\
\hline IPL & 0.44 & 0.32 & 3 & 0.56 & 0.28 & 0 \\
2PL & 0.55 & 0.28 & 1 & 0.65 & 0.26 & 0 \\
3PL & 0.64 & 0.27 & 0 & 0.59 & 0.24 & 0 \\
3PL-C & - & - & - & 0.71 & 0.25 & 0 \\
\hline
\end{tabular}

model. For FSP-RO data, the situation is much the same, including the worsening of the fit when the 3PL model is fitted by considering omissions as fractionally correct responses.

Approximate item chi-square statistics are provided in Table 4. As in the previous study, for both data sets the 1PL model tended to fit worse than the 2PL or 3PL models, both of which did about equally well.

(a) FSP-NC data
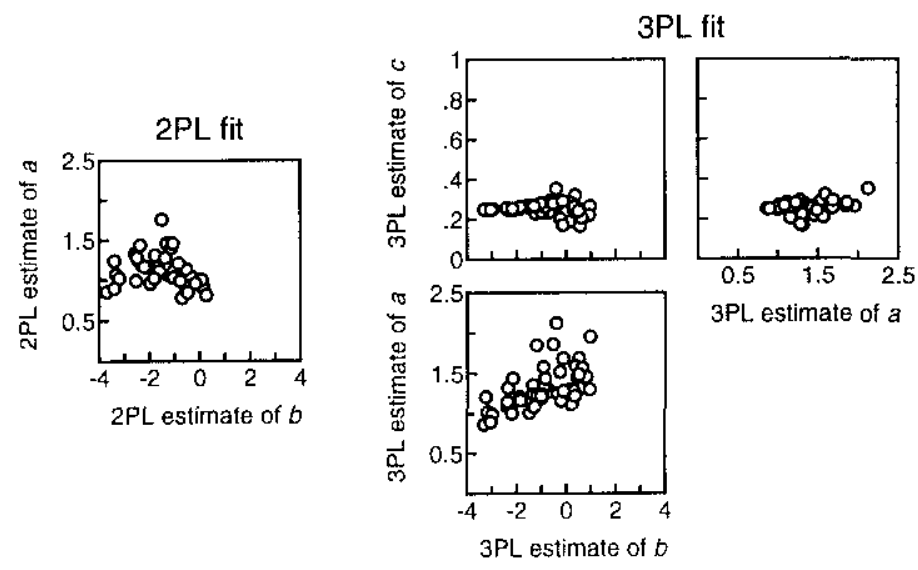

(b) FSP-RO data
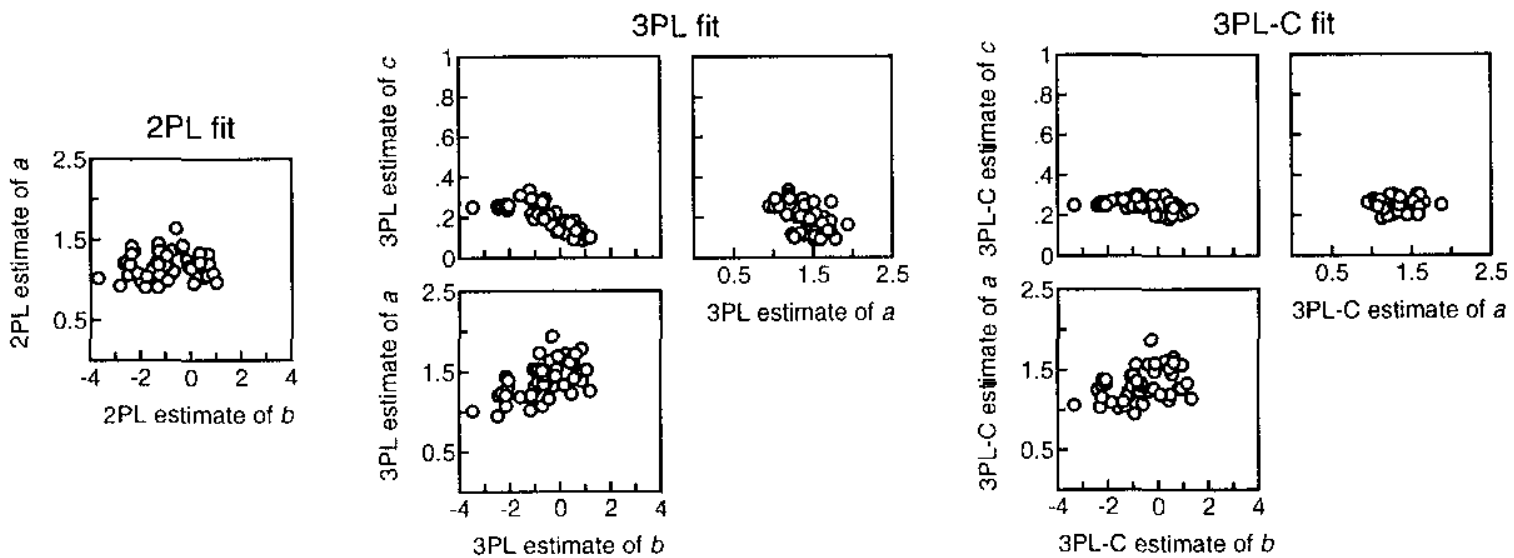

Figure 8. Relations between estimated logistic parameters within each fitted logistic model, (a) FSP-NC data. (b) FSP-RO data. 
Comparing the patterns in Tables 3 and 4 with those in Tables 1 and 2, one would be tempted to say that logistic models fit FSP data better than they fit logistic data! However, the different data and the different parameter spaces involved in each generating model make any such comparison unfair. Other FSP models or other distributions for the truc parameters could possibly be found that would reverse these results. In any case, the conclusion that can reasonably be drawn from these results is that the form of the generating IRF and its associated parameter space goes unnoticed to the logistic function fitling procedure: logistic models can fit FSP data at least no worse than they fit Iogistic data.

Applying again the above-mentioned version of Yen's (1981) first step to determining which logistic model is more appropriate, from Table 4, one would discard the 1PL model on the basis of its comparalively lower mean item $p$-value and the similarity of the means for the $2 \mathrm{PL}$ and $3 \mathrm{PL}$ models. Again, an analysis of the relationships between estimated 2PL and 3PL parameters will be necessary to decide between the 2PL and 3PL models, an analysis that, in this case, will also reveal how logistic function fitting procedures dress the FSP parameter space in logistic costume.

The rclationships between estimated item parameters within each fitted model are shown in Figure 8a for FSP$\mathrm{NC}$ data and in Figure 8b for FSP-RO data. In comparison with analogous plots for logistic data in Figures $1 \mathrm{a}$ and $1 \mathrm{~b}$, the only difference seems to be that the range of the estimated 2PL and 3PL discriminations is somewhat narrower, and the estimated 3PL discriminations are slightly shifted towards lower values than was found for 3PL data. Taking this into consideration, all plots in Figure 8 look very much like those in Figure 1 after a shrinkage of the item discrimination range.

The relationships between estimated item parameters across fitted models are shown in Figure 9. Results for FSPNC data (Figure 9a) are very much like results for 3PL data in Figure 2a if the shrunken item discrimination range is taken into account. Estimated 2PL and 3PL difficulties are more similar to one another than estimated $2 \mathrm{PL}$ and $3 \mathrm{PL}$. discriminations are. Also, items for which the estimated 3PL pseudo-chance parameters deviate the most from the maximal chance level ${ }^{5}$ of .25 tend to be assigned high 2PL difficulty estimates and low 2PL discrimination estimates.

For FSP-RO data, Figure 9b shows estimated 2PL parameters against estimated 3PL parameters obtained when omissions are regarded as wrong responses. Presence of omissions broadens the range of estimated difficulties for both fitted models and further shrinks the range of estimated 2PL and 3PL discriminations. In comparison with Figure 9a, estimated 3PL and 2PL difficulties remain close to one another, and estimated 3PL and 2PL discriminations are more tightly packed than they were in the absence of omissions. On the other hand, and paralleling what was discussed about Figure $2 \mathrm{~b}$ in the previous study, 3PL pseudochance level estimates are below the theoretical chance level of .25 for items with high estimated 2PL difficulty.

If omissions are treated as fractionally correct responses (Figure 9c), the range of estimated 3PL-C discriminations shrinks, and estimated 3PL-C pseudo-chance levels shift back to the same relationship with $2 \mathrm{PL}$ difficulty estimates as they bore in the absence of omissions.

Figure $9 \mathrm{~d}$ shows the relationships between estimated 3PL and 3PL-C item parameters when there are omissions. Just as was pointed out for 3PL-O data in Figure 2d, difficulty estimates are very similar across both fitted models $(r=.99)$, discrimination estimates are only slightly less similar across models ( $r=.94$ ), and pseudo-chance level estimates is where both options for the treatment of omissions differ the most $(r=.75)$.

For these generating FSP models, it is more interesting to see how the various item parameter estimates resulting from fitting logistic models relate to the single true item parameter 8 . Figure 10a shows these relationships for FSPNC data. Estimated 2PL difficulty is highly negatively ${ }^{6}$ related to true $\delta(r=-96)$, and estimated 2PL discrimination is positively related to true $\delta(r=.50)$. When the 3PL model is fitted to FSP-NC data, the relationship between true $\delta$ and estimated difficulty remains the same $(r=-.96)$, estimated discrimination becomes slightly negatively related to true $\delta(r=-.44)$, and estimated pseudo-chance level fails to hold any meaningful relation to true $\delta$ (despite $r=.27$, possibly because the spread of the estimates around .25 is broader when $\delta$ is below .5).

The relations between $\delta$ and estimated logistic parameters from FSP-RO data are shown in Figure 10b. The relation between true $\delta$ and estimated 2PL difficulty is similar to what it was in the absence of omissions $(r=-.98)$ but the relation with estimated 2 PL discrimination vanishes $(r=$ .02 ). When the 3PL model is fitted treating omissions as wrong responses (3PL fit), estimated discrimination is negatively related to true $\delta(r=-56)$, and estimated pseudochance level is highly positively related to true $\delta(r=87)$. When the 3PL-C model is fitted, the relationships between true $\delta$ and estimated logistic parameters are about the same as those found in the absence of omitted responses.

\footnotetext{
5 Bear in mind that, in FSP models, $\delta$ is the only item parameter. In addition, as Figure 7 shows, the theoretical chance level will in gencral be different for different examinees because it equals $\gamma_{j} / n, n$ being the number of options in the item.

6 Bear in mind that $\delta$ in ISSP models decreases with increasing difficulty, whereas $b$ in logistic models increases with increasing difficulty.
} 
(a) FSP-NC data; 2PL vs 3PL fit

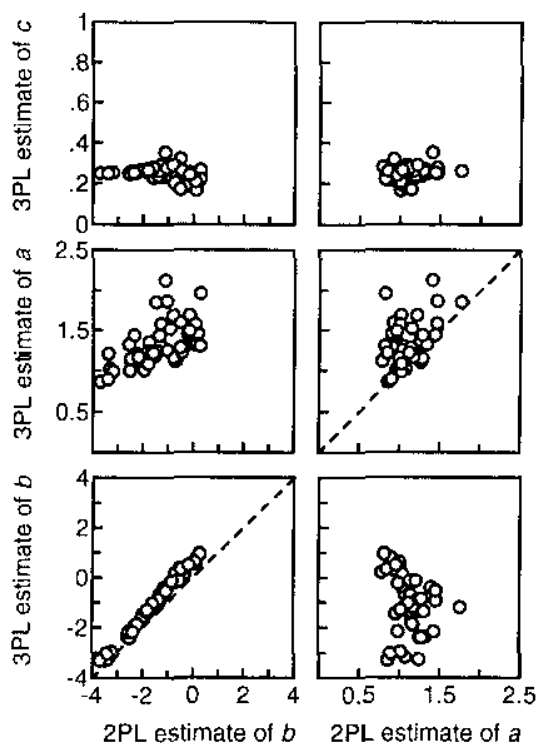

(b) FSP-RO data; 2PL vs 3PL fit

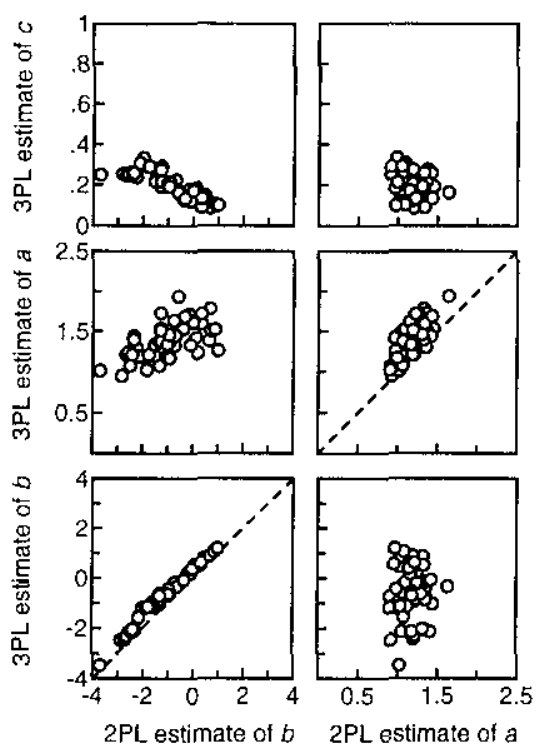

(c) FSP-RO data; $2 \mathrm{PL}$ vs $3 \mathrm{PL}-\mathrm{C}$ fit

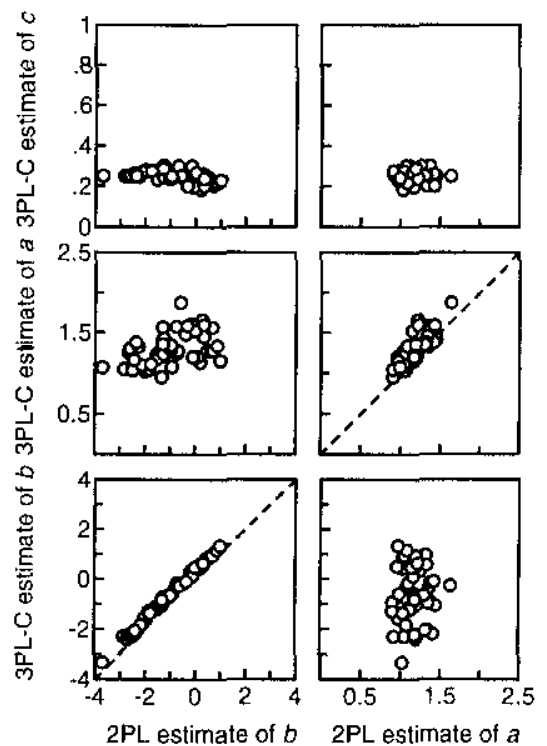

(d) FSP-RO data; 3PL vs 3PL-C fit
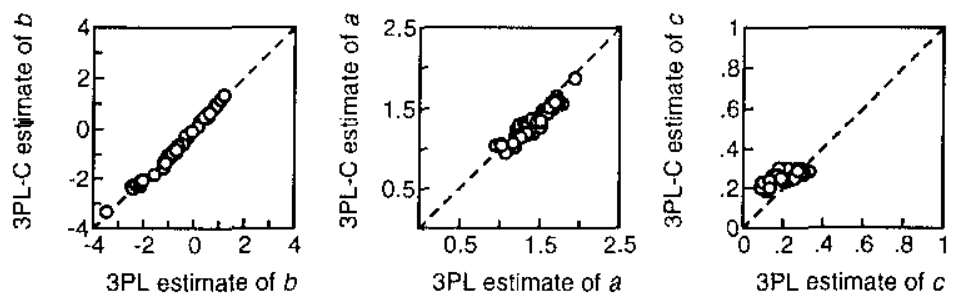

Figure 9. Relations between estimated logistic parameters atcross different fitted logistic models. (a) 2PL vs 3PL estimates for FSP-NC dati. (b) 2PL vs 3PL estimates for FSP-RO data. (c) 2PL vs 3PL-C estimates for IISP-RO data. (d) 3PL vs 3PL-C estimates for FSPRO data. Dashed diagonal lines indicate an expected identity relationship between the variables in the abscissa and the ordinate.

(a) FSP-NC data

2PL fit
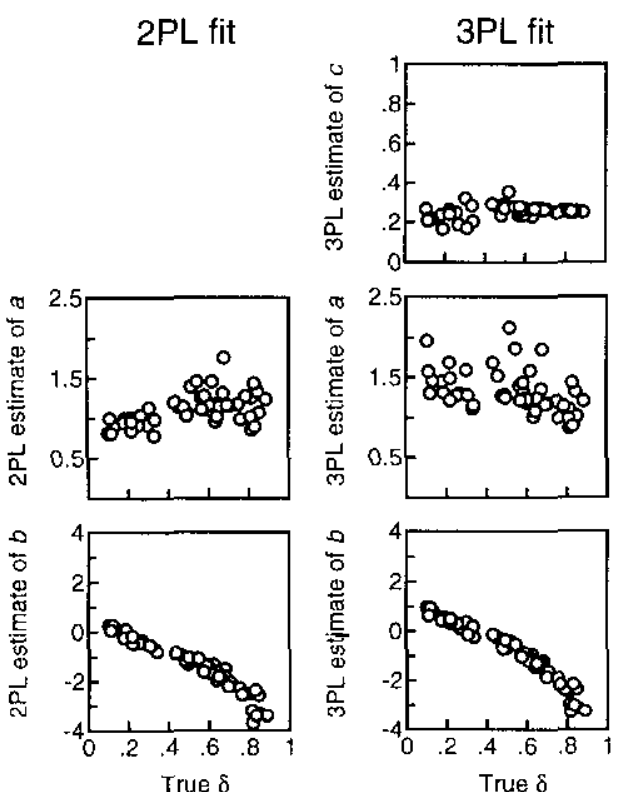

(b) FSP-RO data

2PL fit
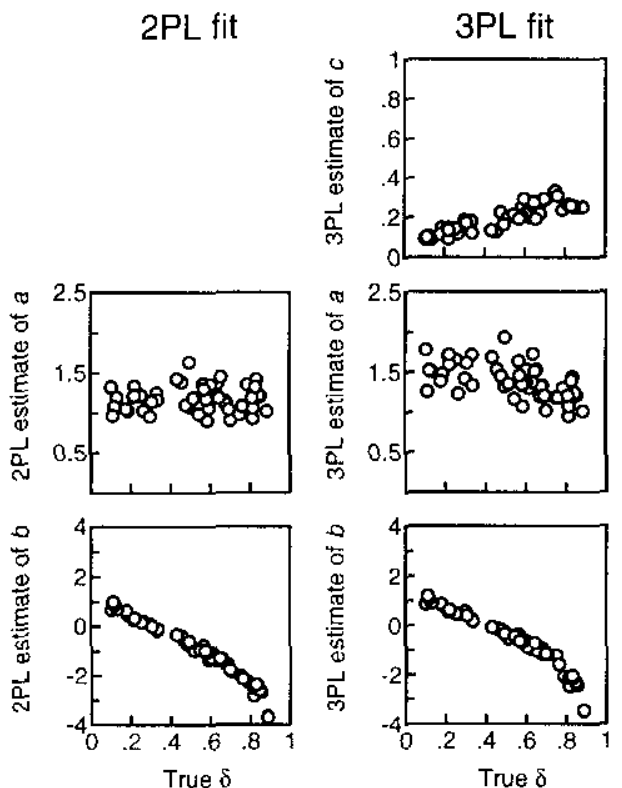

Figure 10. Relations between true $\delta$ and 2PL and 3PL estimates. (a) FSP-NC data. (b) FSP-RO data. 


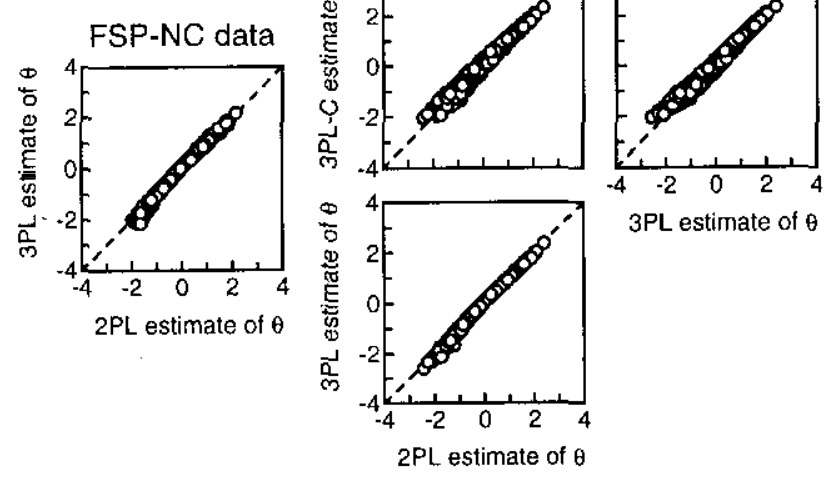

Figure 11. Relations between estimated logistic abilities across modess fitted to each data set. Dashed diagonal lines indicate an expected identity relationship between the variables in the abscissa and the ordinate.

Figure 11 shows that the various $\theta$ s estimated by fitting logistic models to FSP-NC and FSP-RO data are as lincarly related as they were for actual 3PL data in Figure $5(r>$ .98). Figure 12 shows, however, that none of them is as tightly related to actual $\lambda(.93<r<.96)$. It is interesting to note that estimated $\theta$ s were unrelated to true $\gamma$ (an irrelevant factor for the purpose of ability estimation) for FSP-NC data $(|r|<.03)$, but for FSP-RO data they were positively related to true $\gamma(r \approx .23)$. In other words, when omissions are allowed, examinees with higher propensities to guess will spuriously obtain higher logistic ability estimates.

\section{Conclusion}

In all relevant respects, the results of Study 2 are equivalent to those of Study 1 . Tables 3 and 4 , and Figures 8,9 , and 11 for FSP data show statistics and relationships that do not differ from what PC-BILOG produces for actual
3PL data (compare with Tables 1 and 2, and Figures 1, 2, and 5). If Yen's (1981) criteria were used, one would conclude that the 3PL model fits all data from Study 2, and the 3PL parameterization would then be used. The trouble, however, is that its referent constructs do not exist in the reality that generated the data.

Of course, Figures 10 and 12 show that estimated logislic difficulty is highly related to true $\delta$, and that estimated logistic ability is also highly related to true $\lambda$. Then, one might think that there must be transformations-which there are not-that will translate logistic $b$ s into FSP $\delta$ s and logistic Os into FSP $\lambda$ s, and viceversa. Indeed, there is no way to go from one parameter space to the other because the logistic parameterization returns two extra "estimates" of fictitious parameters (item discrimination and pseudo-chance level) and fails to estimate one of the actual parameters ${ }^{7}(\gamma)$. Note also that the recovery of IRFs cannot even be studied when logistic models are fitted to FSP data, because the domains of true and estimated IRFs are incommensurable.

\section{General Discussion}

It is perhaps surprising that the attempt to fit logistic functions where they do not belong can succeed with such flying colors. It seems that in the absence of an external clue as to what type of IRF and parameter space generated the data, trying to fit logistic functions to them is not going to provide one: BILOG produces estimates that bear the same relationships among each other when the inpul are either logistic or FSP data. In other words, application of an off-the-shelf computer program for logistic model parameter estimation produces off-the-shelf results regardless of how similar or different the generating model was from the would-be logistic model.

Routine and pragmatism guide the adoption of logistic IRFs, and most users are content fitting these functions to their data. Actually, Lord (1980, p. 31) explicitly expressed
FSP-NC data

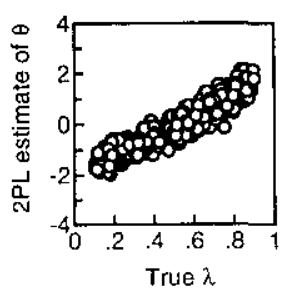

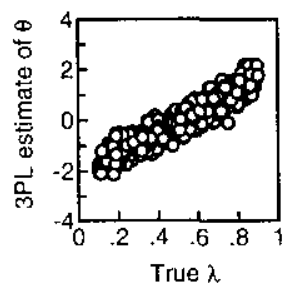
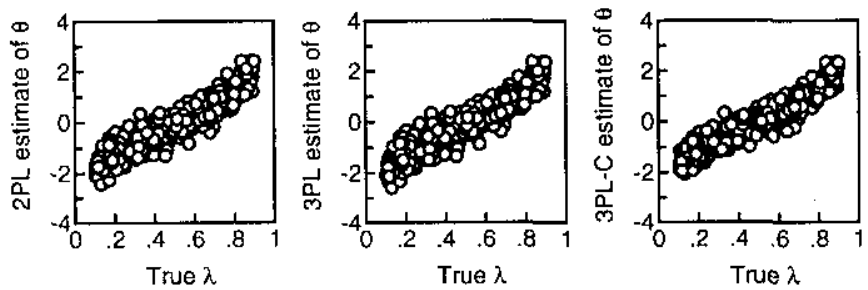

Figure 12. Relations between true $\lambda$ and estimated logistic ability across models fitted to each data set.

\footnotetext{
7 If there are no omissions. this parameter does not need to be estimated.
} 
this pragmatic orientation lowards a preference for logistic IRFs when he claimed that "justification of their use is to be sought in the results achieved, not in further rationalizations." Also, Hambleton and Swaminathan (1985, p. 162) pointed out that "item response models are often chosen as the mode of analysis in order to obtain the advantages [of IRT]." Some authors even regard the capability of fitting data as a manifestation of the maturity of IRT (Thissen \& Steinberg, 1984, p. 518). Under this "good-fit-above-all-else" philosophy, justification for the use of logistic functions could be sought in their "success" at parameterizing the FSP data in Study 2. Yet, it is not clear what kind of success this is. An investigation into the behavior of algorithms for fitting logistic functions is undertaken next. Also, some theoretical and practical consequences of blind adherence to logistic IRFs are commented upon, and the characteristics of FSP IRFs, at alternatives to logistic IRFs, are briefly discussed.

\section{Will Logistic Functions Always Fit Test Data?}

This question needs some qualification, since it is clcar that logistic models will not fit data that are not approximatcly Guttman scalable, and also that the IPL and 2PL models are sometimes rejected in favor of the $3 \mathrm{PL}$ model. However, this is not the issue. For one thing, given the nested hierarchy of logistic models, no one should be surprised that the 3PL model fits better than the 2PL model which, in lurn, fits better than the 1PL model. The issue is whether all three of them can be found to be "not-the-models-that-generated-thedata." In view of the results of Study 2 above, it is hard to imagine how this could happen.
Also, it is fallacious that logistic functions will fit everything. It is well known that better fits are sometimes obtained when a few items that seem to depant from the fitted model are dropped, a practice that has been criticized, apparently with little impact, by Goldstein (1979) and Traub (1983). The results of the first simulation in Study 1 show that one should expect to find a few apparently misfitting items even when the data are generated by the model to be fitted. Therefore, their eventual occurrence in the fitting of logistic models to real test data reveals standard performance of the algorithm and gives added emphasis to the point that estimation algorithms merely try to maximize overall fit, even at the expense of having to tag some items as misfitting.

Moreover, the estimation algorithm seems indeed to focus on obtaining ability estimates with a certain distribution, obtaining along the way whatever item parameters are necessary to achieve this goal. This preference shows in that, for any given data set, estimated item parameters vary much more than examinee parameters across fitted models (see relations between 2PL and 3PL estimates of $b$ and $a$ in Figure 2, and compare with the much tighter relations between 2PL and 3PL estimates of $\theta$ in Figure 5; the same holds for analogous relations arising from FSP data in Figures 9 and 11). Figure 13 shows histograms of the logistic ability estimates obtained from each fitted model for each data set, clearly revealing that estimated logistic abilities wind up having roughly the sume distribution. For logistic data (Figure 13a), the bell-shaped form of these distributions might be taken as a natural consequence of the fact that the data were generated from true os that were

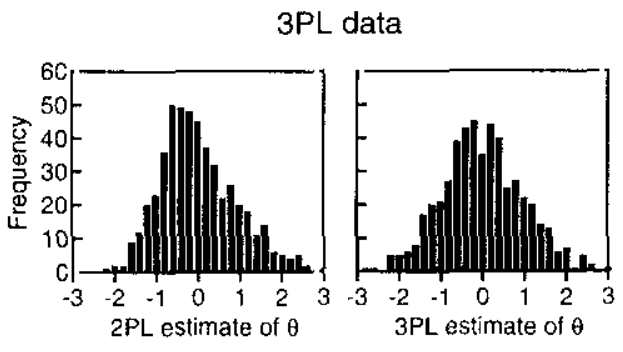

FSP-NC data

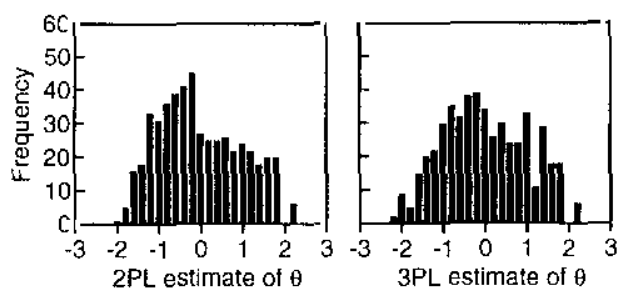

(a)

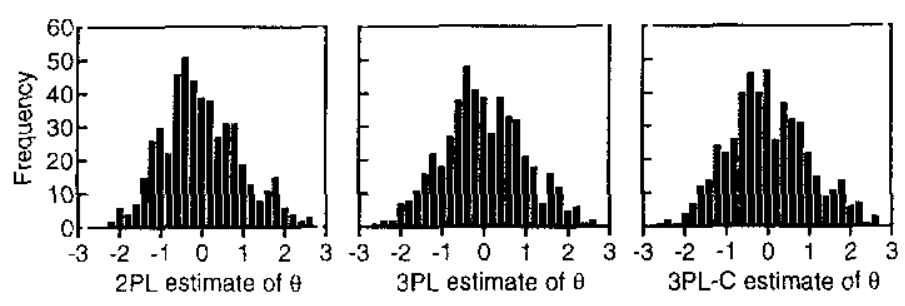

(b)

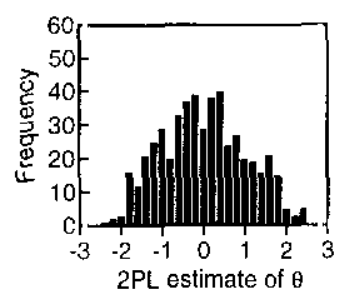

FSP-RO data

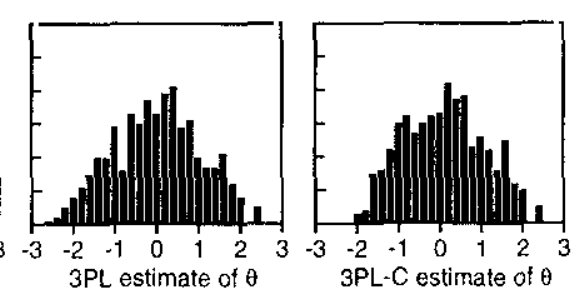

Figure 13. Histograms of the ability estimates obtained by the various nodels fitted to each data set. (a) Logistic data. (b) FSP datia. 
normally distributed. The inappropriateness of this conclusion shows in Figure 13b, which also reveals bell-shaped distributions of estimated logistic abilities despite the actual uniform distributions of the generating FSP $\lambda s$ !

Provided that some basic assumptions hold (see Rosenbaum, 1984), it is easy to understand how logistic models fit data so efficiently. IRT usos very powerful function-fitting procedures to find IRFs by searching for the best solution in the atvailable parameter space. Logistic IRFs define a huge parameter space and do not incorporate any constraint (in the form of variables whose values are empirically measured independently). With so many degrees of freedom, no empirically-constrained independent variable, and a very powerful function-fitting algorithm, it is no wonder that solutions are found. Under these circumstances, failure to fit the data is what would be surprising.

This potential for fitting data derives from an observation by Lord and Novick (1968, p. 369), according to which "whenever any single [IRF] is a monotonic increasing function of $\theta$, it is always possible and permissible to transform $\theta$ monotonically so that the characteristic curve becomes a normal ogive." Hence the power of normal ogive models (or logistic models, for that matter): the function-fitting algorithms implicitly apply the necessary transformation of the authentic ability scale in order to produce the $\theta$ s that logistic models require. This process underlies the Iransformation of $\lambda$ s into $\theta$ s when the logistic model is fitted to FSP data. The forfeit is that $\theta$ becomes only an ordinal measure bearing an unknown relation to the authentic ability.

\section{Are Logistic Models Testable?}

By fitling logistic models to test data, one merely determines whether parameters can be found that will make this general framework account for the data. The search for parameter estimates is made. using the procedures referred to in the previous section, in a way that maximizes a goal function which provides one of the possible sets of bestfitting parameter estimates ${ }^{8}$ Afterwards, the goodness of the fit is measured by making use of those estimates. This procedure involves a circularity (García-Pérez, 1994; GarcíaPérez \& Frary, 1991a; Goldstein \& Wood, 1989) which makes it unlikely that the goodness-of-fit test may result in a recommendation to reject the model.

Testing a model is different from fitting it (Marascuillo, 1988). It implies seeking independent empirical evidence supporting some model prediction. Fitting a model merely implics forcing the data into a theoretical scheme with the help of suitably chosen parameters. Fitting a model that has been successfully tested is legitimate, but fitting a model by fiat is not. In their present form, logistic models are not testable: they cannot make any testable prediction before parameter estimation. The models do not incorporate any observable independent variable, and only one observable dependent variable (a binary response to an item) is involved. Again, it is not surprising that presumed "tests" of the model using parameters that were estimated to fit the data confirm that the fit was actually obtained.

\section{What Are the Consequences of Inappropriate Use of the 3PL Model?}

Some misinterpretations that result from the failure to acknowledge the metaphoric nature of logistic models and their parameter space can easily be traced. For instance, when 3PI. models are fitted to real test data, pseudo-chance level estimates are often found to have values far from the theoretical chance levels. This has been taken as evidence that examinees of low ability are attracted towards distractors in some items, thus performing below the guessing level, whereas, on other items, even examinees of low ability can eliminate some distractors, thus bringing the lower asymptotes above the guessing level (Lord, 1974). However, this interpretation sounds as appealing as it is unrealistic: a look at Figure 1 shows that this effect also occurs in a simulation in which there were no real items, distractors, or examinees to climinate or be atracted to them, and where the true pseudo-chance levels were set at 0.25 . Figure 8 shows the same pattern in a simulation involving a response process and a parameter spacc other than logistic. In view of this, the onty sensible way to interpret these fluctuations is that they are an artifact of the fitting algorithm that does not reveal any underlying reality."

Similarly unfounded conclusions were raised by Thissen and Steinberg (1984). Their model for multiple-choice items results in non-monotonic tracc lines (IRFs) for the correct option in some itcms. This made them introduce the concept of "positive misinformation," which would permit low-ability examinees to give the right answer for the wrong reason. Again, the interpretation sounds reasonable and may imply a phenomenon that exists in reality but, instead of looking for direct empirical evidence of the actual phenomenon, the explanation was accepted at once without further ado in order to accommodate the outcomes of a model that the data was forced to fit by fiat.

Finally, Yen, Burket, and Sykes (1991) have shown that the likelithood equation for a non-trivial amount of real response vectors to multiple-choicc items under the three-

\footnotetext{
8 Alternative sets of estimates are obrained by changing the goal function in the parameter estimation method.

1) The foregoing discussion does not deny the existence of partial information and misinformation. It simply claims that fluctuations of the estimates of $c$ around the theorelical chance level have nothing to do with them.
} 
parameter logistic model may have several local maxima of similar magnitude at widely different ability levels. The obvious consequence of this characteristic is a necessary introduclion of uncertainty in ability estimation. Although only one of these will be a global maximum for any given response vector, they also showed that LOGIST did not always find this global maximum, and they were unable to determine the conditions under which the global maximum would be found. They acknowledged that this state of affairs is unsatisfactory, but they also explained away the problem by claiming that the occurrence of multiple maxima in the likelihood function for a particular response vector indicates that, rather than being inconsistent with the model, the response vector is consistent with the model in more than one way: that response vector might arise either from high ability or from low ability combined with successful guesses. Yet, no direct empirical evidence was provided to substantiate this interpretation.

The three examples just mentioned derive from an endemic feature of logistic models: the disregard for a representation of the response process. Partial information, misinformation, guessing, omitting, etc, are not properly represented in a model which simply states that the probability of a correct response to an item is given by a reasonablelooking function of ill-defined parameters. The situation is specially troublesome when the model is asked to fit data sets where guessing has been part of the response process, and where omissions may also have occurred. This situation led Baker (1987a, p. 135) to demand that "some effort shoukd be devoled to developing a new model to cope with the issue of guessing," It is noteworthy how difficult it has proved to imvestigate and determine the effect of omissions or guessing on logistic fit. This is simply because there is no prescription as to how this should be done: there is no model-consistent way of introducing omissions or guessing in a data set. If this is done, it can be done in various ways (e.g., Lord, 1983; Mislevy \& Bock, 1982; Wainer \& Wright, 1980; Waller, 1989) each of which affects fit differently.

The simulations in Study 2 provide the basis for an assessment of the consequences of using the 3PL model when it does not hold (however well it fits). The losses associated with not using the adequate model are especially dramatic on theoretical grounds. According to Gulliksen (1961, p. 101), psychometric models should establish "the relation between the ability of the individual and his observed score on the test." But establishing that relationship implies an exercise in substantive theory and model building before any function is fitted to the data.

The first advantage of using a theoretically sound and empirically appropriate model is that claims to the effect that an examinee has an ability of, say, 0.7 would be meaningful. In logistic models, $\theta$ does not have units of measurement, nor is it related to any quantitative measure of knowledge or ability. Indeed, Lord (1975, p. 205) defined the ability scale as "the scale on which all itcm characteristic curves have some specified mathematical form, for example, logistic or normal ogive," thus expressing a clear disregard for the interpretability of $\theta$. As a consequence, under the metric of $\log$ istic JRFs, ability estimates only reveal relative performance and, thus, that an examinee has an ability of 0.7 means, at the most, that his or her ability is greater than those of examinees obtaining lower ability estimates. But how much ability he or she has remains anknown.

Also, if the IRF embodied assumptions about the format of the test and the way it is administered, about examinee behavior, and about other characteristics of the testing situation, then these assumptions could be replaced to obtain IRFs applying to a variety of circumstances. As a result. Gulliksen's (1961, pp. 101-102) wish of being "able to say that, for certain specificd tests constructed in this way, here is the relationship between the score and the ability measured, and this is the appropriate trace line to use" will be closer to becoming fullilled. In addition. IRT methods could easily be used with items that are not binary scored. It would also be possible to determine theoretically what combination of these characteristics gives rise to more accurate ability estimates, thus providing a basis for advising in favor of or against certain testing practices. FSP models have indeed been successfully used for this purpose. For instance, García-Pérez (1989a) used FSP models to show that mastery decisions with any given practical degree of accuracy require dramatically different numbers of items depending on the format of administration of the test and the guessing bebavior adopted by the examinees. Also, Garcia-Pcrez (1993) used FSP models to show that use of "none of the above" has the important advatutage of reducing the size of the confidence intervals for maximum-likelihood estimation of $\lambda$, as compared to those of analogous conventional items with the same number of options. of course, the extent to which these theoretical outcomes turn into advantages in empirical testing practice depends on the empirical validity of FSP models, an issue that will be commented on in the next section.

\section{Is There an Altemative?}

As discussed by García-Pérez and Frary (1991a), finite state theory produces IRFs that are free of the problems inherent to logistic functions. Potential benefits of using FSP IRFs in place of their logistic counterparts are also discussed there. For purposes of comparison with the picture of logistic IRFs that emerges from the simulations in Study 2 and the foregoing discussion, a lew of the contrasting ficatures of FSP IRFs will be mentioned here.

First, finite slate models have mechanislic realism. They are built on parameters that are empirically meaningful, consider assumptions about how items are constructed, how lests are abministered, and how examinees behave and, then, translate literally a description of test-taking behavior into mathematical terms. As a result, as many equations are 
produced as there are response outcomes under the format of administration considered, each of which is interpretable on its own. For instance, in Equation 3a above, the probability of a correct response is expressed as the sum of the probabilities of all the situations that may lead the examinee to give the correct answer to the item of concern, from knowledge of the truth value of all options in the item (first addend in Equation 3a), through knowledge of three options (second addend), knowledge of two options, one of which is the correct answer (third addend), successful guess in case of knowledge of two options that are distractors (fourth addend), knowledge of only one option that turns out to be the correct answer (fifth addend), and successful guess in case of knowledge of only one distractor (sixth addend), to a successful guess under total ignorance (seventh addend). Equations $3 b$ and $3 c$ similarly embody the circumstances that may lead an examinee to mark a wrong option or omit the item. By doing so, FSP modess incorporate realistically all the relevant concepts in test-taking behavior: total knowledge, partial knowledge, total ignorance, and guessing. García-Pérez and Frary (199la) discuss how misinformation can be incorporated into finite state models, as well as how to use this framework for speeded tests.

Second, FSP IRFs are testable. Although, like their logistic counterparts, FSP IRFs hypothesize the relationship between correct responses on a test and a number of unobservable parameters, FSP models include additional equations for the relationships of these unobservable parameters with the remaining response outcomes under a given format of administration of a test. It is all these explicit relationships that allow deriving model predictions that can be tested without estimating model parameters. This provides the grounds for testing (and, then, accepting or rejecting) the models before searching for parameters that will maximize model fit. Empirical examples of FSP model testing can be found in García-Pérez (1987, 1990; see also Garcia-Pérez \& Frary, 1991b; Zin, 1992).

Finally, FSP models incorporate an interpretable definition of ability. This point was sufficiently illustrated when the models were introduced at the beginning of Study 2, and will not be further expanded upon here. It should be pointed out that FSP models do not include an item discrimination parameter, but there is no a priori reason why a psychometric model would be incomplete if it did not have one. That logistic functions with them fit data better than logistic functions without them is a result that is local to logistic functions. The adequacy of an alternative IRF is to be measured by its accomplishments, and not by how it compares conceptually with the IRFs for which it is an alternative.

A final question about the qualifications of FSP models as an alternative to logistic models is whether they are ready for use, especially in what regards parameter estimation methods. García-Pérez (1985, 1987, 1989b) and García-Pérez and Frary (1989) described simple analytical methods for the estimation of $\lambda$ that proceed by consideration that all items have identical, average difficulty. García-Pérez (1993, 1994) described and studied alternative methods for the estimation of $\lambda$ that make use of the same assumption (items of identical, average difficulty), but relying on the optimization of goal functions derived from the minimum-distance measures of (a) FSP-NC data
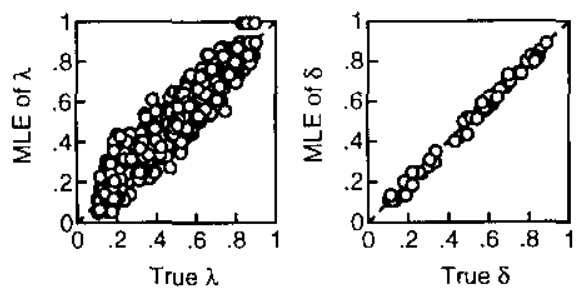

(b) FSP-RO data
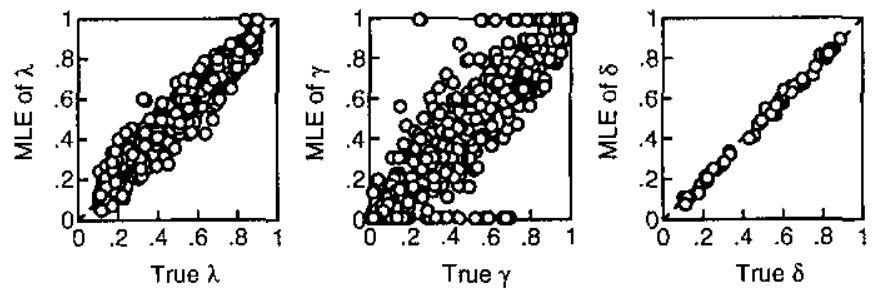

(c) FSP-NC vs FSP-RO estimates

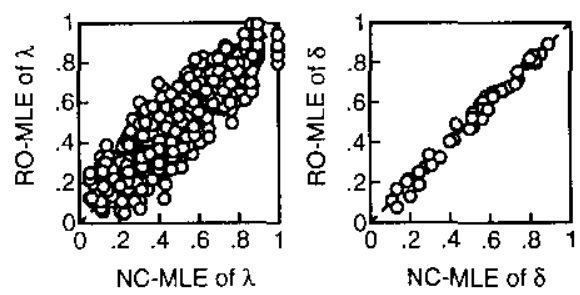

Figure 14. Relations between true and MLEs of FSP parameters in each data set [(a) for FSP-NC data; (b) for FSP-RO data]. and between MLEs of $\lambda$ and $\delta$ across data sets (c). Dashed diagonal lines indicate an expected identity relationship between the variables in the alsccissa and the ordinate. 
Cressie and Read (1984), which include the populat minimum chi-square and maximum likelihood methods. Application of these methods for the estimation of all relevant parameters $(\lambda$ and $\delta$ from FSP-NC data and $\lambda, \gamma$, and $\delta$ from FSP-RO data) is straightforward, and Figures $14 a$ and $14 b$ show the relalionships between true parameters and their maximumlikelihood estimates (MLEs) for the FSP-NC and FSP-RO data sets from the simulations in Study 2. Note that MLFs of $\delta$ are much more accurate than MLEs of $\lambda$ (and $\gamma$, where applicable), but this is only a result of the fact that estimates of 8 are each based on responses from 500 examinees, whereas estimates of $\lambda$ are each based on responses 1050 items (i.e., a factor of ten fewer data). The estimation of $\gamma$ is further hampered because opportunities to guess are scarce for medium- and high-ibility examinees and, therefore. random variations dominate the data on which the estimation of $\gamma$ is based. This noise does not affect MLEs of $\lambda$, which can be seen to be equally linearly related to true $\lambda$ when there are omissions (Figure $14 b ; r=.95$ ) and when all items are answered (Figure 14a; $r=.96$ ). Finally, Figure $14 \mathrm{c}$ shows that MLEs of $\lambda$ from FSP-NC vs FSP-RO data are less related to one another $(r=90)$ than either of them is to true $\lambda$.

\section{References}

Albanese, M.A. (1988). The projected impact of the correction for guessing on individual scores. Jommal of Educafional Measuremen, 25, 149-157.

Ansley, T.N., \& Forsyth, R.A. (1985). An examinalion of the characteristics of unidimensional IRT parameter estimates derived from two-dimensional data. Applied Psychological Measurement, 9, 37-48.

Baker, F.B. (1987a). Methodology review: Item parameter estimation under the one-, two-, and three-parameter logistic models. Applied Psychological Measurement, 11. 111-141.

Baker, F.B. (1987b). Item parameter estimation via minimum logit chi-square. British Journal of Mathematical and Statistical Psychology, 40, 50-60.

Baker, F.B. (1991). Comparison of minimum logit chi-square and Bayesian item parameter estimalion. British Jommal of Mathematical and Statistical Psychology, 44, 299-313.

Baker, F.B. (1998). An investigation of the jtem parameter recovery characteristics of a Gibbs samping procedure. Applied Psychological Measurement, 22, 153-169.

Bejar, 1.1. (1983). Introduction to item response nodels and their assumptions. In R.K. Hambleton (Ed.), Applications of ikm response theory (pp. 1-23). Vancouver, BC: Educational Research Institute of British Columbia.

Blinkhorn. S.F. (1997). Past imperfect, tuture conditional: Fifty years of test theory. British Journal of Mathematical and Statistical Psychology, 50, 175-185.

Bliss. L.B. (1980). A test of Lord's assumption regarding examinee guessing behavior on multiple-choice tests using elementary school students. Jounal of Educational Measurement, 17, 147-153.
Cressic. N., \& Read. T.R.C. (1984). Multinomial goodness-of-fit ICsis. Joumal of the Royal Statistical Society. Series B. 46 , 440-464.

Cross. L.H., \& Frary, R.B. (1977). An empirical test of Lord's theoretical tesults regarding formula scoring of multiple choice tests. Joumal of Edhe ational Me'tsurement, 14, 313-321.

De Ayala. R.J. (1992). The influence of dimensionality on CAT ability estimation. Liducatronal and Pswhological Meawrement, 52. $513-528$.

Dinero, T.E., \& Haertel, E. (1977). Applicability of the Rasch model with varying item discriminations. Applied Psychological Measurement. 1, 581-592.

Drasgow, F. \& Parsons, C.K. (1983). Application of unidimensional item response theory models to multidimensional data, Applied Psychological Measurement, 7, 189-199.

Forsych, R.. Saisangjan, U., d Gilmer, J. (1981). Some empirical results related to the robustness of the Rasch model. Applied Psychological Medwurement, 5, 175-186.

Freedman. D.A. (1985). Statistics and the scientific method. In W.M. Mason \& S.E. Fientery (Eds.), Cohont analysis in social research: Beyond the identification problem (pp. 343-366). Now York: Springer-Verlag.

Garcíi-Pérè M.A. (1985). A linite state theory of performance in multiple-choice tests. In E. Terouanne (Ed.). Procectings of the to $0^{\text {th }}$ Earopean mahematical prychology group neeting (pp. 55-67). Montpellier: European Mathematical Psychology Gronp.

Garcia-Péze. M.A. (1987). A finite state theory of performance in multiple-choice tests. In E.E. Roskam \& R. Suck (Eds.), Progress in mathematical psychologv-l (pp. 455-464). Amsterdam: Elsevier:

García-Péres, M.A. (1989a). Item sampling, guessing, partial information and decision-making in achicvement testing. In L.E. Roskam (Ed.). Mathematical psychology in progress (PP. 249-265). Berlin: Springer-Verlag.

García-Pérez. M.A. (1989b). La corrección del azar en prucbas objetivas: un enfoque basado en una nueva teoría de estados finitos. Investigaciones Psicológicas, 6, 33-62.

García-Pérez, M.A. (1990). A comparison of two models of performance in objective lests: Finite states versus continuous distributions. British Jonrmal of Mathematical and Statistical Psychology, 43, 73-91.

García-Pcrez, M.A. (1993). In defence of "none of the above." Britivh Joumat of Mathematical and Statistical Psychology, 46. 213-229.

Garcia-Pérez. M.A. (1994). Parameter estimation and goodnessof-fit testing in mulcinomial models. British Joumal of Mathomatical and Statistical Psycholagy, 47, 247-282.

Garcia-Pérez, M.A., \& lirary, R.B. (1989), Psychometric properties of finite-state scores versus number-contect and formula scores: A simulation study. Applicd Pswchological Measwanent, I3, 403-417.

García-Pérez, M.A., \& Frary, R.B. (199 la). Finite state polynomic item characteristic curves. British Joumal of Mathematical and Statisfical Psychology, 44, 45-73. 
Garcia-Pérez, M.A., \& Frary, R.B. (199/b). Testing finite state models of performance in objective tests usitog items with 'none of the above' as an option. In J.-P. Doignon \& J.-C. Falmagne (Eds.), Mathematical psychology: Current developments (pp. 273-291). New York: Springer-Verlag.

Gifford, J.A., \& Swaminathan, H. (1990). Bias and the effect of priors in Bayesian estimation of parameters of item responsc models. Applied Prychological Measurement, 14, 33-43.

Goldstein. H. (1979). Consequences of using the Rasch model for educational assessment. Brizish Edacational Research Joumal, $5,211-220$

Goldstein, H.. \& Wood, R. (1989). Five decades of item response modelling. British Journal of Mathematical and Statistical Psychology, 42. 139-167.

Gulliksen. H. (1961). Measurement of learning and mental abilities. Psychometrika, 26, 9,8-107.

Hambleton, R.K. (1983). Application of item response models to critcrion-referenced assessment. Applied Psychological Measurement. 7, 33-44.

Hambleton, R.K., \& Cook. L.L. (1983). Robustness of item response models and effects of test length and sample size on the precision of ability estimates. In D.J, Weiss (Ed.), New horizons in testing: Latent trait test theory and computerized adaptive testing (pp. 31-49). Now York: Academic Press.

Hambleton, R.K., \& Murray, L.N. (1983). Some goodness of fit investigations for item response models. In R.K. Hambleton (Ed.), Applications of item response theory (pp. 71-94). Vancouver. BC: Educational Research Institute of British Columbia.

Hambleton, R.K., \& Swaminathan, H. (1985). ltem response theory: Principles and application., Boston, MA: Kluwer.

Harrison, D.A. (1986). Robustness of IRT parameter estimation to violations of the unidimensionalicy assumption. Joumal of Educational Statistics, 1I, 91-115.

Harwell. M.R., \& Janosky, J.F. (1991). An enpirical study of the effects of small datasets and varying prior variances on item parameter estimation in BILOG. Applied Psychological Measurement. 15, 279-291.

Hulin, C.L., Lissak, R.l., \& Drisgow, F. (1982). Recovery of twoand three-parameter logistic item characteristic curves; A Monte Carlo study. Applied Psychological Meanuremen, 6, 249-260.

Jannarone, R.J., Yu, K.F., \& Laughlin, J.E. (1990). Easy Bayes estimation for Rasch-type models. Psychometrika, 55, 449-460.

Kim. J.K.. \& Nicewander, W.A. (1993). Nbility estimation for conventional tests. Prychometrika, 58, 587-599.

Kim, S.-H., Cohen, A.S., Baker, F.B., Subkoviak. M.J.. \& Leonard, T. (1994). An investigation of hierarchical Bayes procedures in item response thcory. Psychometrika, 59, 405-421.

Lord, F.M. (1974). Estimation of latent ability and item parameters when there are omitted responses. Piychometrika, 39, 247 264.

Lord. F.M. (1975). The 'ability' scale in item characteristic curve theory. Psychomatrika, 40, 205-217.

Lord, F.M. (1980), Applications of itent response theory to practical iesting problems. Hillsdale. NJ: Erlbaum.
Lord, F.M. (1983). Maximnum likelihood estimation of item response parameters when some responses are omitted. Psychomerika. $48,477-482$.

Lord, F.M. (1986). Maximum likelihood and Bayesian parameter estimation in item response theory. Joumal of Educutional Measurement, 23, 157-162.

Lord, F.M., \& Novick, M.R. (1968). Statistical theories of mental test scores. Rcading. MA: Addison-Wesley.

Marascuitlo. L.A. (1988). Introduction to model building and rank tests. Contemporary Psychology, 33, 794-795.

Mckinley, R.L., \& Mills, C.N. (1985). A comparison of several goodiess-of-fit statistics. Applied Prychological Measurement, $9,49-57$.

Mislevy, R.J. (1987). Bayes modal estimation in item response models. Psychomerika, 51, 177-195.

Mislevy, R.J., \& Bock R.D. (1982). Biweight estimates of latent ability. Educational and Psychological Measurement, 42. 725 737.

Mislevy, R.J., \& Bock, R.D. (1984). BLLOG version 2.2: llem analysis and test scoring with binary logistic mode?s. Mooresville, IN: Scientific Software.

Mislevy, R.J., \& Bock, R.D. (1986). PC-BLLOG: Item analysis and test scoring with binary logistic models. 1986 edition. Mooresville, IN: Scientific Software.

Mislevy, R.J., \& Stocking, M.L. (1989). A consumer's guide to LOGIST and BILOG. Applied Psychological Measurement, 13,57-75.

Mislevy. R.J., \& Verhelst, N. (1987). Modeling item responses when different subjects employ differen solution strategies. Research Report RR-87-47-ONR. Princeton, NJ: Educational Testing Service.

Ramsay, J.O., \& Abrahamowicz, M. (1989). Binomial tegression with monotone splines: A psychometric application. Journal of the Anerican Statistical Association, 84, 906-915.

Reckase, M.D. (1979). Unifactor latent trait models applied to multifactor tests: Results and implications. Journal of Educational Statistics, 4, 207-230.

Rec. M.J. (1979). Estimating item characteristic curves. Applied Psychological Meawurement, 3, 371-385.

Rosenbaum, P.R. (1984). Testing the conditional independence and monotonicity assumptions of item response theory. Psychometrika, 49, 425-435.

Rowley, G.L.. \& Traub, R.E. (1977). Formula scoring. numberright scoring, and test-taking strategy. Journal of Educationd Measwrement, 14, 15-22.

Scong, 'T.-J. (1990). Sensitivity of marginal maximum likelehood estimation of item and ability parameters to the characteristics of the prior ability distributions. Applied Psychological Measurement. 14. 299-311.

Skaggs, G., \& Stevenson, J. (1989), A comparison of pseudobayesian and joint maximum likelihood procedures for estimating item parameters in the three-parameter IRT model. Applied Psychological Measurement, I3, 391-402.

Slakter, M. (1968). The penalty for not guessing. Journal of Edurational Measurement, 5, 141-144. 
Swaminathan, H., \& Gifford, J.A. (1983). Estimation of parameters in the three-parameter latent trait model. In D.J. Weiss (Ed.). New horizons in testing: Latent trait test theory and computerized adaptwe testing (pp. 13-30). New York: Academic Press.

Swaminathan, H. \& Gifford, J.A. (1986). Bayesian estimation in the three-parameter logistic model. Pinchometrika, 57, 589. 601 .

Thissen, D., \& Steinberg. L. (1984). A response model for multiple doice itens. Psyctometrika, 49,501-519.

Traub, R.E. (1983). A priori considerations in choosing an item response model. In R.K. Hambleton (Ed.). Applications of item response theory (pp. 57-70). Vancouver, BC: Educational Rescarch Institute of British Cofumbia.

Tsutakawa, R.K. (1992). Prior distribution for item response curves. British Journal of Mathematical and Statistical Psychology, $45,51-74$.

Tsutakawa, R.K., \& Johnson, J.C. (1990). The effect of uncertainty of itesn parameter estimation on ability estimates. Psychometrika, 55, 371-390.

Tsutakawa, R.K., \& Lin, H.Y. (1986). Bayesian estimation of item response curves. Psychometrika, 5/, 251-267.

Tsutakawa, R.K., \& Soltys, M.J. (1988). Approximation for Bayesian ability estimation. Joumal of Educational Statistics, 13, 117-130.

Vale, C.D., \& Gialluca, K.A. (1988). Evaluation of the effrciency of item calibration. Applied Psychological Measurement. 12, $53-67$.

Wainer. H., \& Thissen, D. (1987). Estimating ability with the wrong model. Joumal of Educarional Statistics. 12, 339-368

Wainer, H., \& Wright, B.D. (1980). Robust estimation of ability in the Rasch model. Psychometrika, 45, 373-391.

Waller, M.I. (1989). Modeling guessing behavior: A comparison of two IRT models. Applied Psychological Measurement, 33 , 233-243.

Wang, T., \& Vispoel, W.P. (1998). Properties of ability estimation methods in computerized adaptive testing. Joumal of Educational Meastrement, 35, 109-135.
Warm, A.W. (1989). Weighted likelihood cstimation of ability in ilem response theory with tests of finite length. Psychomerika. 54, 427-450.

Weiss, D.J., \& Yoes, M.E. (1991), ltem response theory. In R.K. Hambleton \& J.N. Zaal (Eds.). Advances in edicational and prychological testing: Theory and applications (pp. 69-95). Boston, MA: Kluwer.

Weitzman. R.A. (1996). The Risch model plus guessing. Educational and Psychological Measurement, 56. 779-790.

Wichmann, B.A., \& Hill, I.D. (1982). Algorthm AS 183. An eflicient and portable pseudo-randon number generator. Applied Statisfics, 31, 188-190.

Wingersky, M.S., Barton. M.A., \& Lord, F.M. (1982). LOGIST 5.0 verwion l.0 users' guide. Princeton. NJ: Educational Testing Service.

Wood. R. (1978). Fitting the Rasch model-A heady tale. British Jownal of Mothentatical and Statistical Psychology, 31, 2732.

Yen. W.M. (1981), Using simulation results to choose at latent trait model. Applied Psychological Measurement, 5, 245-262.

Yen. W.M. (1984). Effects of local item dependence on the fit and equating performance of the three-parameter logistic model. Applied Psychological Meawrement, \&, 125-145.

Yen, W.M. (1987). A comparison of the efficiency and accuracy of BILOG and LOGIST. Pswchometrika, 52, 275-29I.

Yen, W.M., Burket, G.R., \& Sykes, R.C. (1991). Nomunique solutions to the likelihood equation for the three-parameter logistic model. Psychometrika, 56, 39-54.

Zeng. L. (1997). Implementation of marginal Bayesian estimation with four-parameter beta prior distributions. Applied Prichological Measurement, 21, 143-156.

Zin. T.T. (1992). Comparing 12 finite state models of examinee performance an maliple-choice tests. Ph.D. Dissertation. Virginia Polytechnic Institute and State University.

Received Decmber 21, 1998 Revision received January 20, 1999 Accepted March 3, 1999 